\title{
Numerical modelling of thermo-active piles in London Clay
}

Klementyna A. Gawecka MEng, ACGI

Research Postgraduate, Department of Civil and Environmental

Engineering, Imperial College London, London, UK

David M. G. Taborda MEng, PhD, DIC

Lecturer, Department of Civil and Environmental Engineering, Imperial College London, London, UK

David M. Potts BSC, PhD, DSC, FREng, FICE, FCGI

GCG Professor of Geotechnical Engineering, Department of Civil and Environmental Engineering, Imperial College London, London, UK
Wenjie Cui BSC, MSC, PhD, DIC

Postdoctoral Researcher, Department of Civil and Environmental

Engineering, Imperial College London, London, UK

(corresponding author: w.cui11@imperial.ac.uk)

Lidija Zdravković MEng, MSc, PhD, DIC

Professor of Computational Geomechanics, Department of Civil and

Environmental Engineering, Imperial College London, London, UK

Muhamad S. Haji Kasri MEng, ACGI

Student, Department of Civil and Environmental Engineering,

Imperial College London, London, UK

Thermo-active foundations utilise heat energy stored in the ground to provide a reliable and effective means of space heating and cooling. Previous studies have shown that the effects of temperature changes on their response are highly dependent on their interaction with the surrounding ground. Consequently, it is necessary to consider this interaction and include both the thermal and mechanical behaviour of the ground in design. This paper addresses this issue by performing state-of-the-art finite-element analyses using the Imperial College Finite Element Program, which is capable of simulating the fully coupled thermo-hydro-mechanical behaviour of porous materials. First, the Lambeth College pile test is analysed to demonstrate the capability of the adopted modelling approach to capture the observed response under thermo-mechanical loading. Subsequently, a detailed study is carried out, demonstrating the impact of capturing the fully coupled thermo-hydro-mechanical response of the ground, the use of appropriate boundary conditions and the uncertainty surrounding thermal ground properties. It is demonstrated that the modelling approach has a large impact on the computed results, and therefore potentially on the design of thermo-active piles. Conversely, the effects of thermal conductivity and permeability of the soil are shown not to influence the pile behaviour significantly.

\section{Notation}

$a, b, r, s \quad$ degradation parameters

$c^{\prime} \quad$ cohesion

$E \quad$ Young's modulus

$E_{\mathrm{d}} \quad$ deviatoric strain invariant

$G_{\max } \quad$ maximum shear modulus

$G_{\text {tan }} \quad$ tangent shear modulus

$G_{0} \quad$ maximum shear modulus at a reference mean effective stress

$K_{\mathrm{f}} \quad$ bulk modulus of pore fluid

$K_{\max } \quad$ maximum bulk modulus

$K_{\mathrm{s}} \quad$ bulk modulus of soil skeleton

$K_{\text {tan }} \quad$ tangent bulk modulus

$K_{0} \quad$ maximum bulk modulus at a reference mean effective stress

$k \quad$ permeability

$k_{0}, B \quad$ non-linear permeability model parameters

$m_{G}, m_{K} \quad$ parameters defining the dependence of elastic stiffness on mean effective stress

n porosity

$p^{\prime} \quad$ mean effective stress

$p_{\text {ref }}^{\prime} \quad$ reference mean effective stress

$\begin{array}{ll}R_{G, \min } & \text { minimum normalised value of } G_{\mathrm{tan}} \\ R_{K, \text { min }} & \text { minimum normalised value of } K_{\mathrm{tan}} \\ T_{\mathrm{p}} & \text { temperature of thermo-active pile } \\ \alpha_{\mathrm{f}} & \text { linear coefficient of thermal expansion of pore fluid } \\ \alpha_{\mathrm{s}} & \text { linear coefficient of thermal expansion of soil } \\ & \text { skeleton } \\ \gamma_{\mathrm{s}} & \text { specific weight } \\ \Delta T & \text { change in temperature } \\ \Delta u & \text { change in pore water pressure } \\ \varepsilon_{\mathrm{vol}} & \text { volumetric strain invariant } \\ \lambda & \text { thermal conductivity } \\ \mu & \text { Poisson ratio } \\ \rho C_{p} & \text { volumetric heat capacity } \\ \phi^{\prime} & \text { angle of shearing resistance } \\ \psi^{\prime} & \text { angle of dilation }\end{array}$

\section{Introduction}

Geothermal energy, that is, the thermal energy beneath the earth's surface, is a renewable energy source capable of providing a reliable means of space heating and cooling. Below a depth of $10-15 \mathrm{~m}$, the ground temperature is constant 
throughout the year and approximately equal to the mean annual air temperature (Banks, 2012). Hence, in the summer the temperature of the ground is lower than that at the surface, whereas in the winter it is higher. Ground source energy systems (GSES) utilise this temperature difference, allowing storage of excess heat in the ground during the summer months and its extraction for heating in the winter. They can be classified as either open-loop systems, which exchange heat with the ground by directly pumping water into or out of the ground, or closed-loop systems, where a fluid is circulated through a series of pipes buried in the ground. One advantage of closedloop systems is the possibility of installing the heat exchanger pipes inside building foundations, retaining walls or tunnel linings, thus providing not only stability but also renewable space heating and cooling. However, this relatively new technology creates challenges for geotechnical engineers as the prediction of the temperature effects on both the structure and the surrounding soil usually requires advanced numerical analysis. Although very few issues regarding the serviceability of such structures have been reported (Loveridge and Powrie, 2013), this may be due to highly conservative design procedures rather than the lack of thermal effects.

Thermo-active piles, which are the subject of this paper, are the most extensively studied geothermal structures. The fullscale field experiments reported by Brandl (2006), Laloui et al. (2006), Bourne-Webb et al. (2009), Akrouch et al. (2014), Mimouni and Laloui (2015), Murphy et al. (2014) and Wang et al. (2015), as well as experimental set-ups by McCartney and Rosenberg (2011), Kalantidou et al. (2012), Stewart and McCartney (2013), Ng et al. (2014) and Yavari et al. (2014a) have provided an invaluable insight into the behaviour of thermo-active piles. Moreover, the results of the first field tests (Bourne-Webb et al., 2009; Brandl, 2006; Laloui et al., 2006) have led to the development of a simplified descriptive framework for thermo-mechanical pile response (Amatya et al., 2012; Bourne-Webb et al., 2013). However, despite the available research, aspects of the interaction between the pile and the surrounding soil require further investigation, especially in terms of the long-term performance under operational conditions.

In order to improve our understanding of thermo-active piles, numerous numerical studies have been performed. For example, Knellwolf et al. (2011), McCartney and Rosenberg (2011) and Suryatriyastuti et al. (2014) used the load transfer $(t-z)$ approach, which includes the effect of thermal expansion and contraction of the pile. The finite-element method has been employed by Laloui et al. (2006), Suryatriyastuti et al. (2012), Bodas Freitas et al. (2013), Dupray et al. (2014), Di Donna and Laloui (2015), Rotta Loria et al. (2015), Salciarini et al. (2015), Bourne-Webb et al. (2016) and Di Donna et al. (2016), among others. Such studies focus on reproduction of the experimental data and/or investigation of various aspects of the soil-structure interaction, including the effects of the soil's thermal expansion coefficient, pile length, ground surface temperature, thermal loads, as well as cyclic heating and cooling. It should be noted that these numerical analyses vary in complexity in terms of both the finite-element formulation and the modelling approach.

This paper presents a detailed numerical study performed using the Imperial College Finite Element Program (ICFEP) (Potts and Zdravković, 1999), which is capable of simulating the fully coupled thermo-hydro-mechanical (THM) behaviour of porous materials. The THM finite-element formulation, including thermal boundary conditions, is detailed in Cui (2015). First, the capabilities of the numerical model are demonstrated by back-analysing the Lambeth College pile test (Bourne-Webb et al., 2009). Reproduction of this field experiment has previously been attempted by several researchers. Ouyang et al. (2011) and Bailie (2013) used the load-transfer method which simulates thermal effects as a mechanical expansion of the beam representing the pile. The finite-element method was adopted by Ozudogru et al. (2015), where the focus was on the modelling of the pile-soil interface without simulating the heat transfer in the soil, as well as Yavari et al. (2014b) and Yavari et al. (2015), who performed uncoupled analyses where the soil was modelled as linear elastic-perfectly plastic. Recently, Abdelaziz and Ozudogru (2016) combined the finite-element method, to simulate the heat transfer in the pile and the soil, with the load transfer approach, to approximate the thermal stresses.

This research aims to improve on these predictions by performing fully coupled THM analysis and employing a modelling approach typical of engineering practice when designing geotechnical structures in London Clay (e.g. underdrained pore water pressure profile, small-strain stiffness, pressure-dependent permeability). In the second part of this paper, the aim is to explain the thermo-mechanical behaviour of piles through an explorative study on a single thermo-active pile installed in ground conditions typical of the London basin. Several aspects that impact the design of geothermal piles are investigated, including the influence of the modelling approach, the application of the thermal load and the uncertainties in the determination of the soil's properties such as thermal conductivity and permeability.

The sign convention adopted throughout this paper is such that compressive normal stresses, compressive strains and downward shear stresses applied to the pile are positive.

\section{Back-analysis of Lambeth College pile test}

Prior to the construction of a new building at Lambeth College in south London, a pile loading test, which also included cycles of heating and cooling, was performed and reported by Bourne-Webb et al. (2009). As one of the first field experiments of this type, it significantly improved our understanding of the thermo-mechanical response of geothermal 
piles and contributed to the development of a simplified framework explaining qualitatively their behaviour (Amatya et al., 2012; Bourne-Webb et al., 2013).

\section{$2.1 \quad$ Test set-up and monitoring}

The test pile was $23 \mathrm{~m}$ long and had a diameter of $550 \mathrm{~mm}$, except in the upper $5 \mathrm{~m}$ where additional casing increased the diameter to $610 \mathrm{~mm}$. Two U-shaped heat exchanger pipes were attached to the reinforcement cage together with 18 vibratingwire strain gauges (VWSGs), six thermistors and optical fibre sensors (OFSs) which provided continuous strain and temperature measurements. Additionally, temperature was recorded in a borehole and anchor piles located $0.5 \mathrm{~m}$ and $2 \mathrm{~m}$, respectively, away from the test pile. The vertical displacement of the pile head was measured using linear variable differential transformers (LVDTs). The mechanical load on the pile was controlled using a load cell and a hydraulic jacket, whereas the thermal load was applied by an $8 \mathrm{~kW}$ heat pump, which allowed circulation of fluid with temperatures ranging from $-6^{\circ} \mathrm{C}$ to $+56^{\circ} \mathrm{C}$ around the heat exchanger pipes.

The test, carried out in the summer of 2007, consisted of the following stages

(a) initial loading to $1800 \mathrm{kN}$ followed by unloading

(b) reloading to $1200 \mathrm{kN}$

(c) pile cooling with a constant pile load

(d) intermittent pile heating with a constant pile load

(e) final loading to $3600 \mathrm{kN}$ followed by unloading.

\subsection{Ground characteristics}

The ground conditions at the Lambeth College site are typical of the London basin. As reported by Bourne-Webb et al. (2009), the ground surface elevation is $+25.5 \mathrm{mOD}$ and the ground profile consists of a $1.5 \mathrm{~m}$ thick superficial layer of Made Ground and $2.5 \mathrm{~m}$ of Terrace Gravel, overlying London Clay. The complete ground profile was obtained from available borehole data in the vicinity of the site and was assumed to consist of $60 \mathrm{~m}$ of London Clay, $15 \mathrm{~m}$ of Lambeth Group Clay, $5 \mathrm{~m}$ of Lambeth Group Sand and $10 \mathrm{~m}$ of Thanet Sand, overlying Chalk. The groundwater table was found at $3 \mathrm{~m}$ below ground level, above which the pore water pressure was assumed to be $0 \mathrm{kPa}$. The pore water pressure below the water table prior to the pile test was assumed to be hydrostatic within the Terrace Gravel, Lambeth Group Sand and Thanet Sand and underdrained within the London Clay and Lambeth Group Clay, as shown in Figure 1 . The adopted $K_{0}$ profile is shown in Figure 2. The ground temperature measured at the site before the pile test was between $18^{\circ} \mathrm{C}$ and $20^{\circ} \mathrm{C}$.

\subsection{Numerical analysis}

\subsubsection{General aspects}

The Lambeth College test was reproduced by performing fully coupled THM analyses using ICFEP, accounting for heat

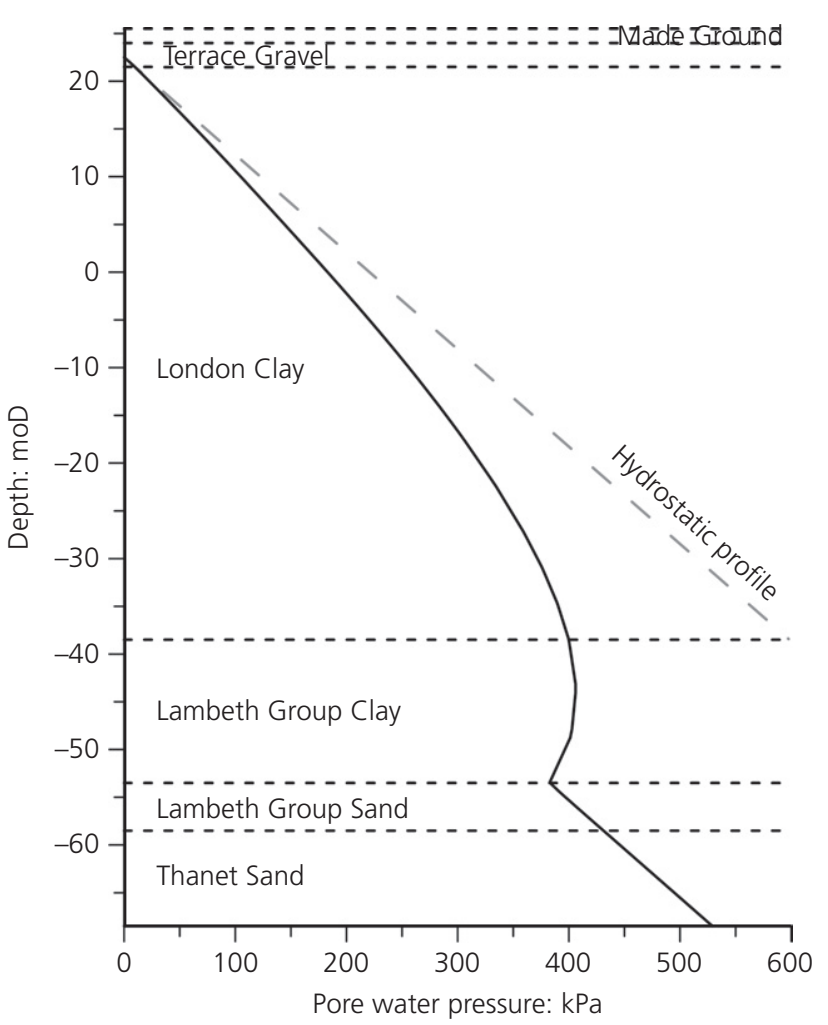

Figure 1. Pore water pressure profile prior to the test

transfer through both conduction and advection. The generation of excess pore water pressures due to the difference between the thermal expansion coefficients of water and soil skeleton was also modelled according to the following equation

1. $\Delta u=\frac{3 n\left(\alpha_{\mathrm{f}}-\alpha_{\mathrm{s}}\right) \Delta T}{n / K_{\mathrm{f}}+1 / K_{\mathrm{s}}}$

The complete finite-element formulation is described in detail in Cui (2015).

It is widely accepted that the stiffness of soils in the small to medium strain range is highly non-linear and must be accounted for in most geotechnical problems (Addenbrooke et al., 1997; Jardine et al., 1986), particularly when the analysed problem is likely to be characterised by limited ground deformations. Based on the magnitude of the strains reported by Bourne-Webb et al. (2009), it is clear that the successful prediction of the soil-structure interaction in the case of the Lambeth College test would require the accurate reproduction of the highly non-linear nature of soil stiffness. In this paper, the Imperial College Generalised Small-Strain Stiffness (IC.G3S) model, which accounts for the effect of a number of variables on the soil stiffness, was adopted in all analyses. Here, the model's capabilities are summarised, with the full details of its formulation being described in Measham et al. (2014) and Taborda et al. (2016). 
Geotechnical Engineering

Volume 170 Issue GE3
Numerical modelling of thermo-active

piles in London Clay

Gawecka, Taborda, Potts et al.

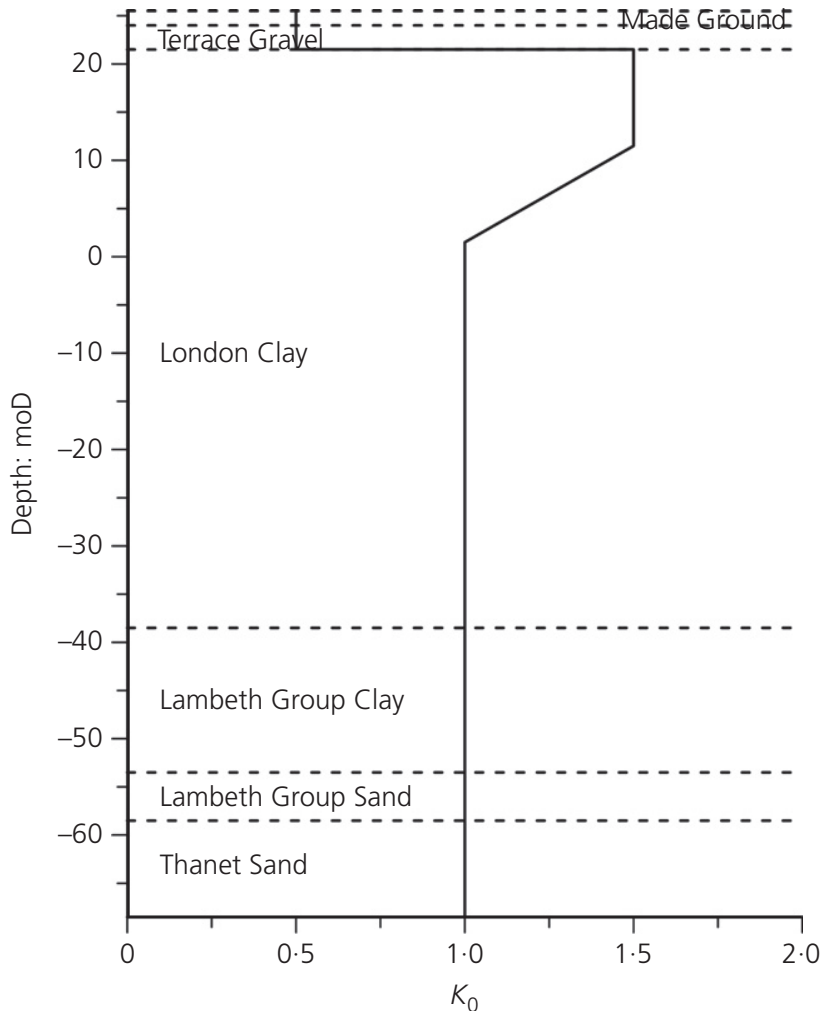

Figure 2. $K_{0}$ profile (based on Schroeder et al., 2004)

The maximum shear and bulk moduli are defined as

2. $G_{\max }=G_{0}\left(\frac{p^{\prime}}{p_{\text {ref }}^{\prime}}\right)^{m_{G}}$

3. $K_{\max }=K_{0}\left(\frac{p^{\prime}}{p_{\text {ref }}^{\prime}}\right)^{m_{K}}$

where the parameters $m_{G}$ and $m_{K}$ control the non-linearity of the stiffness dependency on the mean effective stress.

The degradation of the tangent shear and bulk moduli are calculated using

4. $G_{\mathrm{tan}}=G_{\max }\left[R_{G, \min }+\frac{1-R_{G, \text { min }}}{1+\left(E_{\mathrm{d}} / a\right)^{b}}\right]$

5. $K_{\tan }=K_{\max }\left[R_{K, \min }+\frac{1-R_{K, \min }}{1+\left(\left|\varepsilon_{\mathrm{vol}}\right| / r\right)^{s}}\right]$

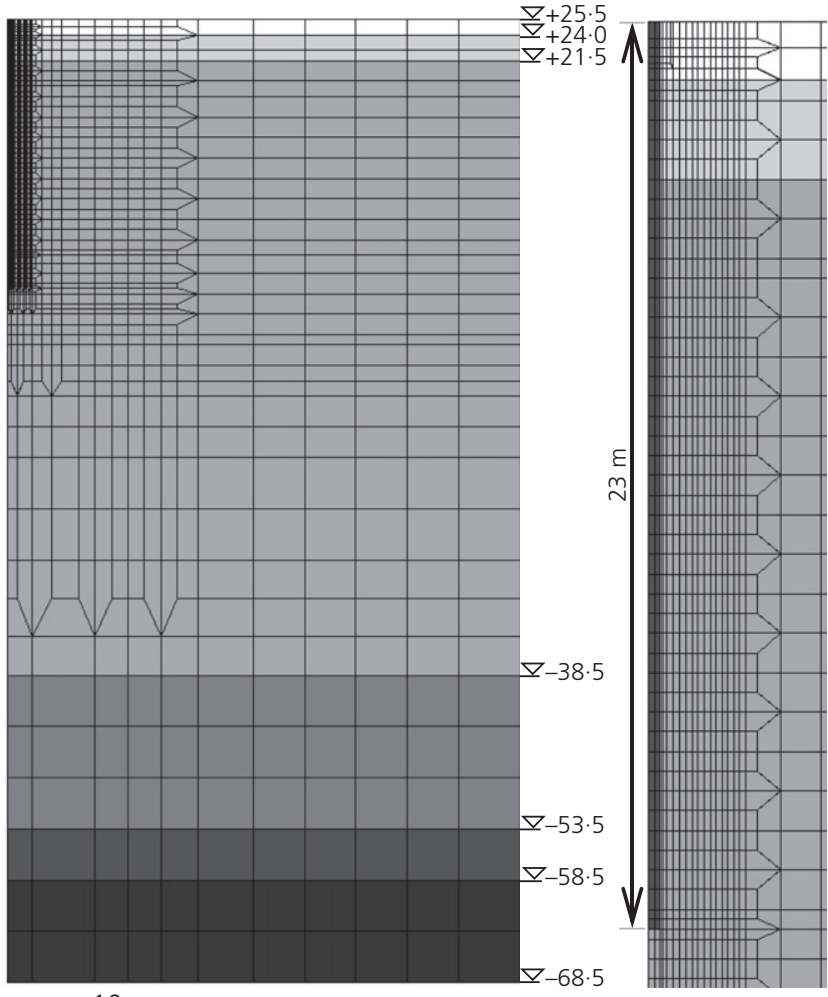

$10 \mathrm{~m}$

(a)

(b)

Figure 3. (a) Finite-element mesh and (b) zoomed-in mesh detailing the pile

The strain invariants are defined as

6. $E_{\mathrm{d}}=\frac{2}{\sqrt{6}} \sqrt{\left(\varepsilon_{1}-\varepsilon_{2}\right)^{2}+\left(\varepsilon_{2}-\varepsilon_{3}\right)^{2}+\left(\varepsilon_{3}-\varepsilon_{1}\right)^{2}}$

7. $\varepsilon_{\mathrm{vol}}=\varepsilon_{1}+\varepsilon_{2}+\varepsilon_{3}$

\subsubsection{Modelling procedure}

Coupled THM axisymmetric analyses have been performed in this paper. Figure 3 shows the finite-element mesh consisting of eight-noded quadrilateral elements where each node has displacement degrees of freedom and the corner nodes have temperature degrees of freedom. For consolidating materials, pore fluid pressure degrees of freedom exist at the corner nodes. It should be noted that, in the model, the pile was assumed to have a constant diameter of $550 \mathrm{~mm}$ throughout its length.

The Made Ground was modelled as linear elasto-plastic with a Mohr-Coulomb failure surface, with the remaining soil layers being modelled as non-linear elasto-plastic with the IC.G3S 
model and a Mohr-Coulomb failure surface. The IC.G3S model was calibrated based on the Jardine et al. (1986) smallstrain stiffness model parameters cited by Schroeder et al. (2004) for a nearby site, as such data for the Lambeth College site are not available. The strength properties were also adopted from Schroeder et al. (2004). The concrete pile was modelled as linear-elastic. The thermal properties reported by Headon et al. (2009) (thermal conductivity and volumetric heat capacity), Bodas Freitas et al. (2013) (thermal expansion coefficient of soil) and Bourne-Webb et al. (2009) (thermal expansion coefficient of concrete) were assumed. All material properties are listed in Tables $1-4$.

\begin{tabular}{lcc}
\hline Material & $E: \mathrm{kPa}$ & $\mu$ \\
\hline Concrete & $40 \times 10^{6}$ & $0 \cdot 3$ \\
Made Ground & $10 \times 10^{3}$ & $0 \cdot 2$
\end{tabular}

Table 1. Linear elastic material properties

\begin{tabular}{lrcc}
\hline Material & $C^{\prime}:$ kPa & $\phi^{\prime}:$ degrees & $\psi^{\prime}$ : degrees \\
\hline Made Ground & 0.0 & 30.0 & 0.0 \\
Terrace Gravel & 0.0 & $35 \cdot 0$ & 17.5 \\
London Clay & $5 \cdot 0$ & 25.0 & 12.5 \\
Lambeth Group Clay & $25 \cdot 0$ & 27.0 & 13.5 \\
Lambeth Group Sand & 0.0 & 34.0 & 17.0 \\
Thanet Sand & 0.0 & 40.0 & 20.0
\end{tabular}

Table 2. Mohr-Coulomb strength properties
The displacement boundary conditions were applied such that the domain was restrained in the radial direction along the left and right vertical mesh boundaries, and in the vertical direction along the bottom boundary. The hydraulic boundary condition included no water flow across the axis of symmetry and no change in pore pressure from the initial condition along the right mesh boundary. The Made Ground, Terrace Gravel, Lambeth Group Sand and Thanet Sand were modelled as non-consolidating free-draining materials. The London Clay and Lambeth Group Clay were consolidating (except for analyses B1 and B2, see Section 3) with a non-linear permeability model where the permeability is related to the mean effective stress through

8. $k=k_{0} \mathrm{e}^{-B p^{\prime}}$

The parameters $k_{0}$ and $B$ were assumed as $1 \cdot 0 \times 10^{-10} \mathrm{~m} / \mathrm{s}$ and 0.0023 , respectively, as suggested by Schroeder et al. (2004). The pore water pressures at the top of the London Clay and at the base of the Lambeth Group Clay were assumed to remain unchanged throughout the analysis. Thermal boundary conditions included no heat flux across the axis of symmetry and no change in temperature from the initial value along the remaining mesh boundaries. The initial pore water pressure and $K_{0}$ profiles used in all analyses are shown in Figures 1 and 2 , respectively, whereas the initial temperature of $19 \cdot 5^{\circ} \mathrm{C}$ was assumed to be constant over the finite-element mesh. As the pile test was carried out during summer months, a constant temperature of $19 \cdot 5^{\circ} \mathrm{C}$ at the ground surface is considered as a reasonable assumption.

All stages of the Lambeth College test described by BourneWebb et al. (2009) were simulated adopting suitable values for

\begin{tabular}{|c|c|c|c|c|c|}
\hline Material & $G_{0}: \mathrm{kPa}$ & a & $b$ & $R_{G, \min }: \mathrm{kPa}$ & $G_{\min }: \mathrm{kPa}$ \\
\hline Terrace Gravel & $41939 \cdot 61$ & 0.000145 & $1 \cdot 0$ & 0.03511 & 3000 \\
\hline London Clay & $51743 \cdot 55$ & 0.000056 & $0 \cdot 9$ & 0.06450 & 2667 \\
\hline Lambeth Group Clay & $51924 \cdot 52$ & 0.000110 & 0.95 & 0.04662 & 2667 \\
\hline Lambeth Group Sand & $81346 \cdot 31$ & 0.000015 & $1 \cdot 0$ & $0 \cdot 14557$ & 1000 \\
\hline Thanet Sand & $65275 \cdot 23$ & 0.000046 & $0 \cdot 85$ & 0.02631 & 2000 \\
\hline Material & $K_{0}: \mathrm{kPa}$ & $r:-$ & s: - & $R_{K, \text { min }}: \mathrm{kPa}$ & $K_{\min }: \mathrm{kPa}$ \\
\hline Terrace Gravel & $49843 \cdot 08$ & 0.000247 & $1 \cdot 25$ & $0 \cdot 15440$ & 3000 \\
\hline London Clay & $26692 \cdot 73$ & 0.000127 & $1 \cdot 8$ & $0 \cdot 13275$ & 5000 \\
\hline Lambeth Group Clay & $61331 \cdot 71$ & 0.000065 & 1.4 & 0.07589 & 5000 \\
\hline Lambeth Group Sand & $49843 \cdot 08$ & 0.000026 & $0 \cdot 9$ & 0.08377 & 5000 \\
\hline Thanet Sand & $29813 \cdot 53$ & 0.000155 & $1 \cdot 1$ & $0 \cdot 27947$ & 5000 \\
\hline
\end{tabular}

Note: $p_{\text {ref }}^{\prime}=100 \mathrm{kPa} ; m_{G}=1.0 ; m_{K}=1.0$ for all strata

Table 3. Small-strain stiffness properties 


\begin{tabular}{lcccccc}
\hline Material & $\gamma_{\mathrm{s}}: \mathrm{kN} / \mathrm{m}^{3}$ & $\alpha_{\mathrm{s}}: \mathrm{m} /(\mathrm{mK})$ & $\alpha_{\mathrm{f}}: \mathrm{m} /(\mathrm{mK})$ & $K_{\mathrm{f}}: \mathrm{GPa}$ & $\rho C_{p}: \mathrm{kJ} /\left(\mathrm{m}^{3} \mathrm{~K}\right)$ & $\lambda: \mathrm{kW} /(\mathrm{mK})$ \\
\hline Concrete & 24.0 & $8.5 \times 10^{-6}$ & - & - & 1920 & $2.33 \times 10^{-3}$ \\
Made Ground & 18.0 & $1.7 \times 10^{-5}$ & - & - & 1900 & $1.40 \times 10^{-3}$ \\
Terrace Gravel & 20.0 & $1.7 \times 10^{-5}$ & - & - & 1900 & $1.40 \times 10^{-3}$ \\
London Clay & 20.0 & $1.7 \times 10^{-5}$ & $6.9 \times 10^{-5}$ & $2 \cdot 2$ & 1820 & $1.79 \times 10^{-3}$ \\
Lambeth Group Clay & 20.0 & $1.7 \times 10^{-5}$ & $6.9 \times 10^{-5}$ & $2 \cdot 2$ & 1760 & $2 \cdot 20 \times 10^{-3}$ \\
Lambeth Group Sand & 20.0 & $1.7 \times 10^{-5}$ & - & - & 1760 & $2 \cdot 20 \times 10^{-3}$ \\
Thanet Sand & 20.0 & $1.7 \times 10^{-5}$ & - & - & 1760 & $2.40 \times 10^{-3}$
\end{tabular}

Table 4. Thermal and thermo-mechanical properties

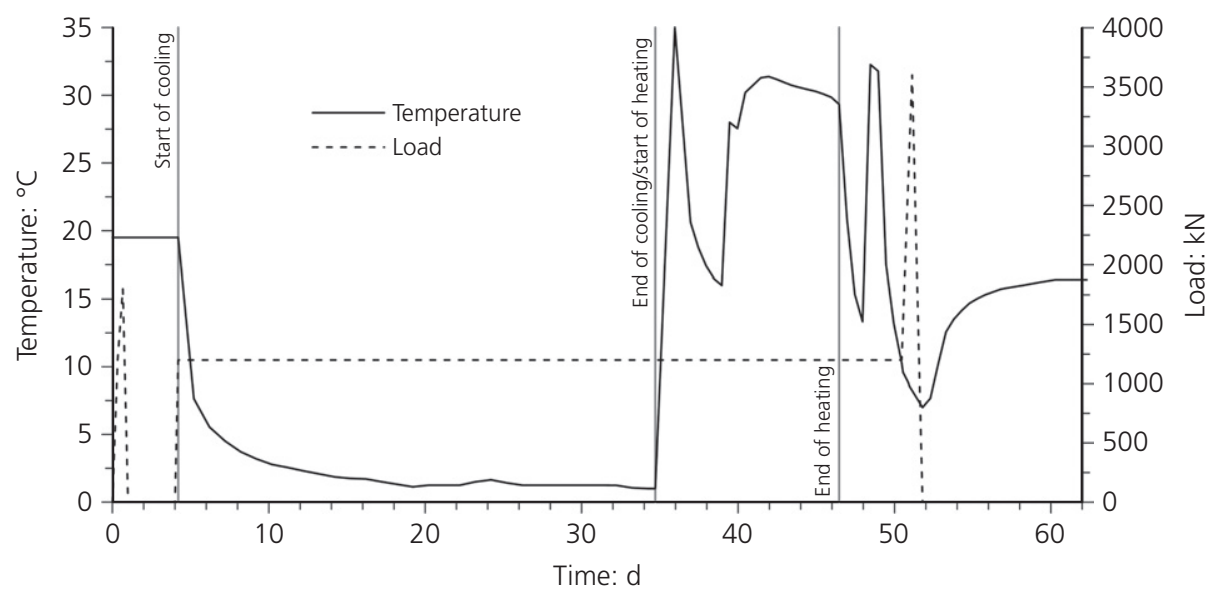

Figure 4. Pile load and temperature recorded in the test pile and applied in the finite-element model

the time step as outlined by Cui et al. (2016). The mechanical and thermal loading sequences are illustrated in Figure 4. The thermal loading was modelled by applying the temperature recorded by the thermistors inside the test pile to a line of nodes in the mesh located at the same distance from the pile centre as the in situ heat exchanger pipes. As reported by Bourne-Webb et al. (2009), the temperature inside the test pile was approximately constant with depth, except the top $2 \mathrm{~m}$ where it was affected by the air temperature. Therefore, the temperature history shown in Figure 4 was prescribed at the abovementioned line of nodes along the entire depth of the pile except for the top $2 \mathrm{~m}$.

It is often observed in laboratory tests that upon a change in the direction of loading (i.e. from loading to unloading or vice versa), the soil stiffness does not continue to degrade and the soil's response is stiffer. The simplest way (for the type of model used here) of simulating this numerically is to zero the values of $E_{\mathrm{d}}$ and $\varepsilon_{\mathrm{vol}}$ used to calculate the tangent stiffness (Equations 4 and 5), resetting the stiffness to its maximum value every time the loading direction is reversed. Although the importance of simulating these reversals associated with mechanical loading has been demonstrated previously (e.g. Schroeder et al., 2004), the effect of resetting the material's stiffness during thermal loading has not yet been investigated. Therefore, three analyses were performed in this part of the paper. In analysis LC1 the resetting procedure was performed at the following stages: before the first unloading from 1800 to $0 \mathrm{kN}$; start of reloading to $1200 \mathrm{kN}$; start of the cooling period; start of the heating period; before the final loading to $3600 \mathrm{kN}$; and at the start of the final unloading. Analysis LC2 included resetting at the same stages as analysis $\mathrm{LC}$, with the exception of the reset before the start of the cooling period. For comparison, in analysis LC3, the stiffness was not reset and was allowed to degrade continuously throughout the analysis (see Measham et al. (2014) for details).

\subsubsection{Results}

The results of the analyses are compared to measurements on site in terms of the temperature in the surrounding soil, as well as the pile head vertical displacement, pile axial strains and shear stress. Figure 5 shows the pile head vertical displacement throughout the test. Although the initial loading to $1800 \mathrm{kN}$ is accurately reproduced, the displacement during the following 


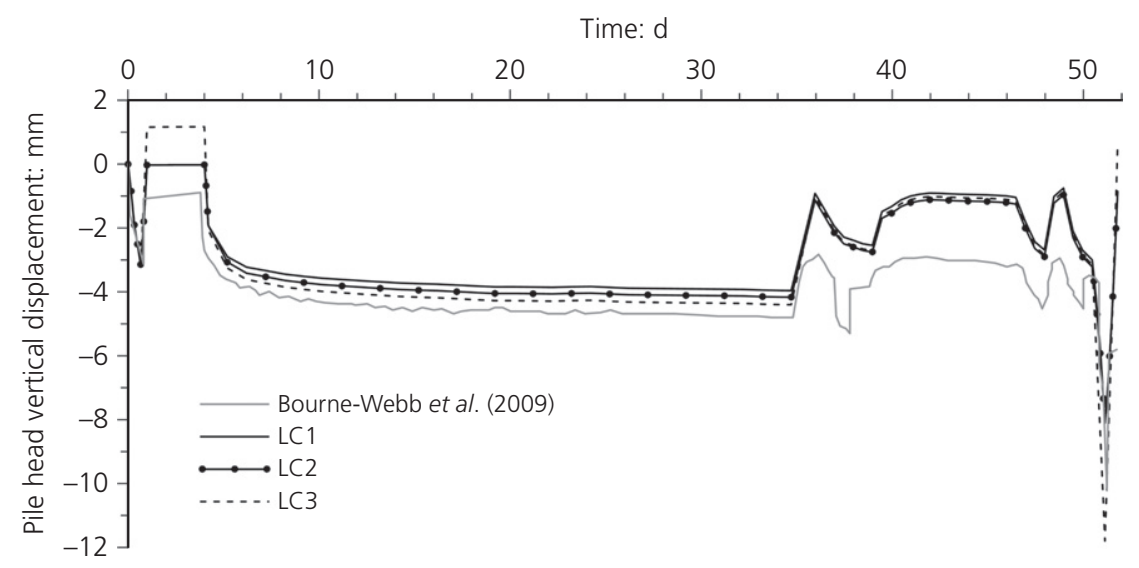

Figure 5. Pile head vertical displacement with time

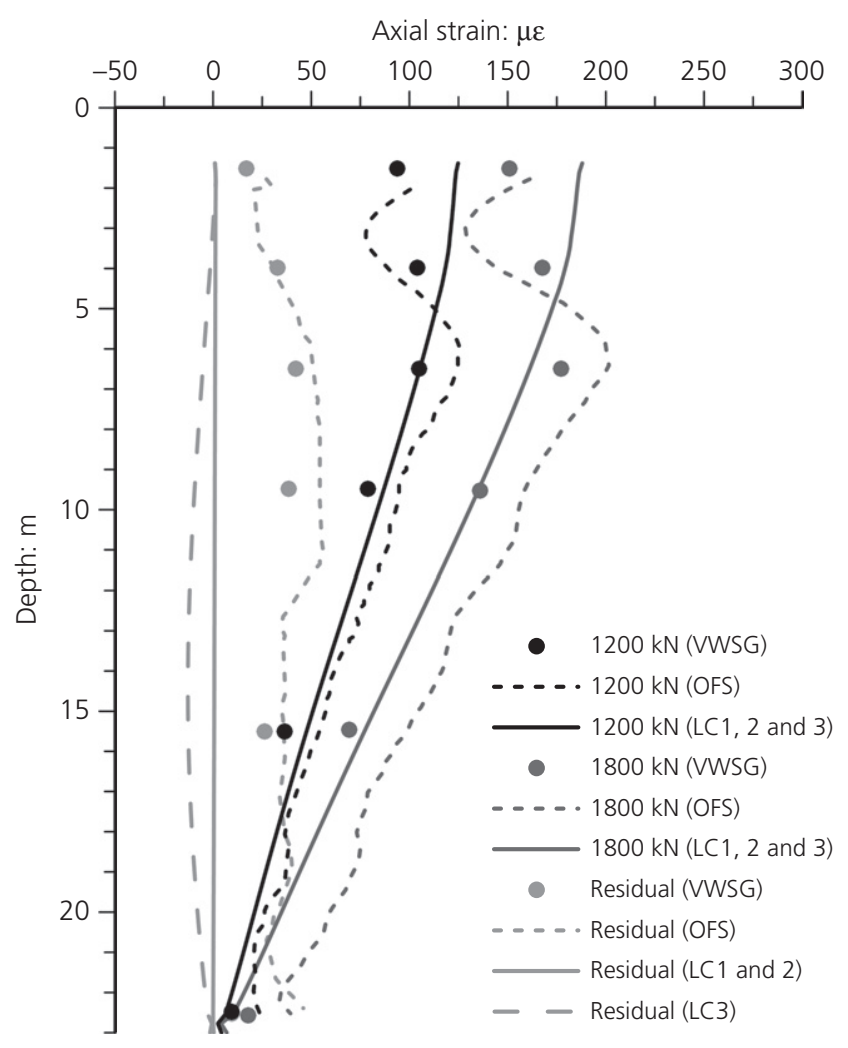

Figure 6. Axial strain profiles in the pile during the initial loading test

unloading stage is overpredicted in all three analyses. Indeed, the field measurements show irreversible pile settlements which could not be simulated in any of the analyses, suggesting that this may involve plastic mechanisms which could not be captured with the simple Mohr-Coulomb failure criterion. However, it should be noted that, as standard design procedures involve the application of factors of safety, such irreversible displacements would be unlikely to take place during the structure's design life. Therefore, the use of the Mohr-Coulomb failure criterion, despite its inherent limitations, is acceptable in the design of geotechnical structures when predicting ground movements. Moreover, the importance of resetting the stiffness is clearly demonstrated by the excessive and unrealistic rebound simulated in analysis LC3, where the stiffness continuously reduces due to the accumulation of strains. The reloading stage to $1200 \mathrm{kN}$ is reproduced well in analyses LC1 and LC2. These observations are also evident in Figure 6 where the axial strain profiles during the initial loading match the field data well.

In order to allow comparison between the analyses for the thermal loading stage of the test, the pile head displacement was offset using the displacement at the start of reloading to $1200 \mathrm{kN}$ as a baseline, as shown in Figure 7. Cooling causes contraction of the pile, and therefore, a downward movement of the pile head. In analysis LC1, the pile settlement is smaller than in analysis LC2 due to a stiffer soil response resulting from resetting the stiffness before the start of cooling. However, the difference in the pile displacement between analyses LC1 and LC2 is small, particularly when compared to that observed in analysis LC3, where the stiffness degrades continuously. This observation suggests that the effect of resetting the stiffness before the thermal loading stage may be less crucial than during the mechanical loading stage.

The numerical predictions of the heating stage are not as close to the field data as those of the cooling stage. The reason for this difference may be soil plasticity and contraction upon heating which has been observed in laboratory tests (e.g. Abuel-Naga et al., 2007; Sultan et al., 2002) and is not accounted for in these analyses.

Figure 8 compares the temperature measured at $9 \mathrm{~m}$ below ground level in the borehole as well as in the anchor pile 


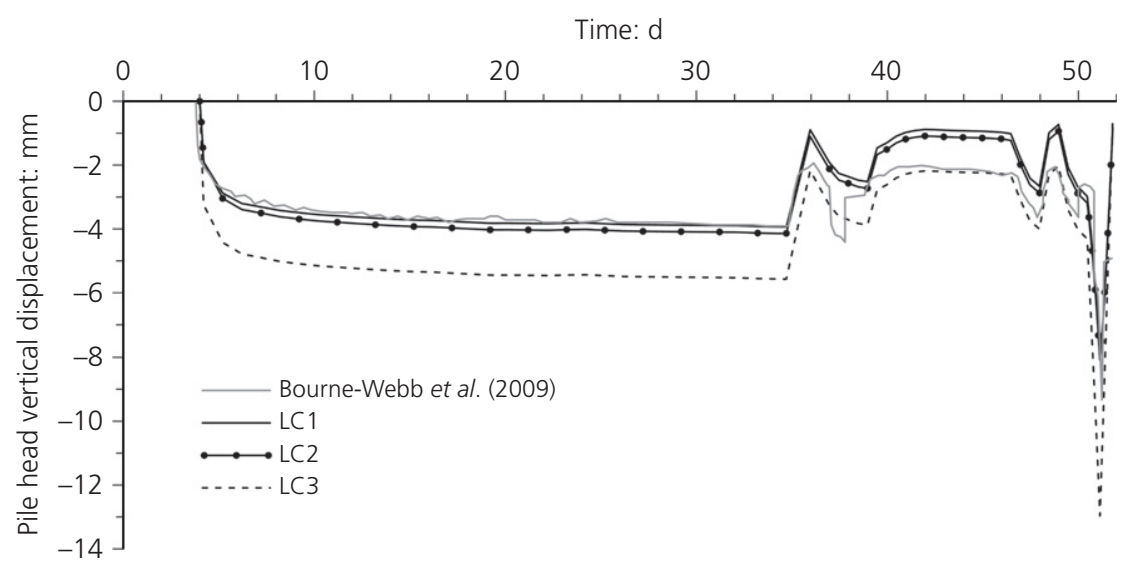

Figure 7. Pile head vertical displacement due to temperature changes with time

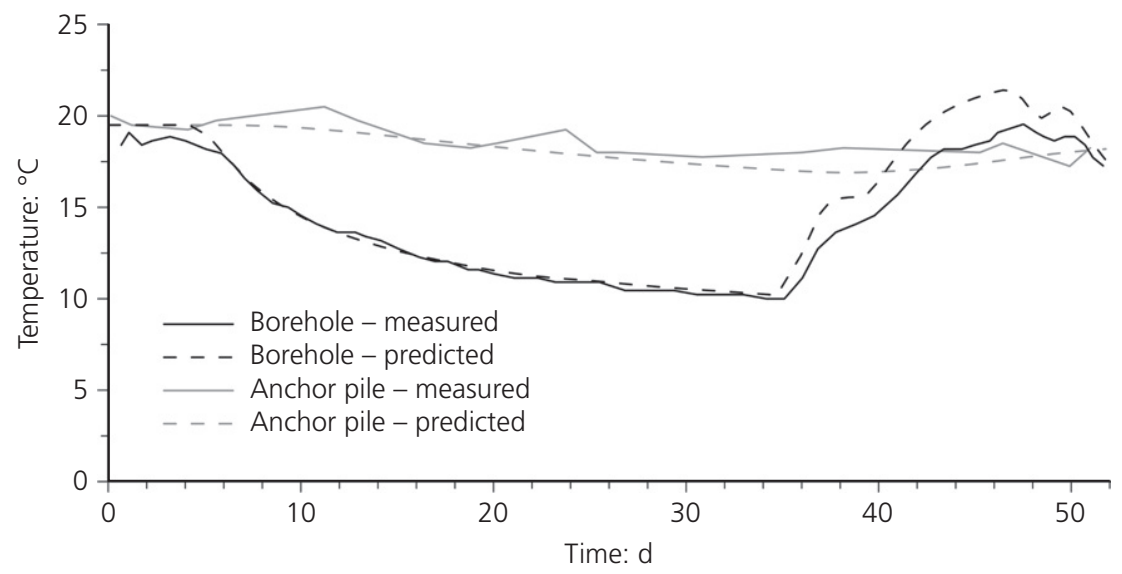

Figure 8. Temperature at borehole and anchor pile with time

(located $0.5 \mathrm{~m}$ and $2 \mathrm{~m}$ away from the test pile, respectively) with the numerical predictions. The temperature in the anchor pile remains relatively constant throughout the test suggesting that the radius of thermal influence of the pile is less than $2 \mathrm{~m}$. The results of the numerical analyses are in a good agreement with the field data, which indicates that the heat transfer is simulated accurately. The slight discrepancy in the temperature at the borehole during the heating stage may also explain the overestimated upward movement of the pile head shown in Figure 7.

The axial strain profiles shown in Figure 9 were offset using the residual strain profile as a baseline. It must also be noted that these strains are the mechanical strains obtained by subtracting the thermal strains, which are calculated as the product of the thermal expansion coefficient of the pile and the change in temperature, from the total observed strains. This was done in order to be consistent with the published field data. Owing to the transfer of heat between the heat exchanger pipes and the concrete, the temperature in the pile is not uniform over its cross-section, resulting in varying axial strains. Therefore, Figure 9 presents the ranges of axial strain, with the extrema typically being observed at the axis and at the circumference of the pile. As suggested by the pile head displacement history, results of analysis LC1 show the best agreement with the field data. However, at the end of heating, all numerical simulations underestimate the axial strain measured in the upper part of the pile, which shows an increase with depth in its first $7 \mathrm{~m}$, indicating a downwards shear stress applied to the pile.

Figure 10 present shear stress on the pile after reloading to $1200 \mathrm{kN}$, end of cooling, as well as end of heating in analysis $\mathrm{LC} 1$, which showed the best reproduction of the field test data.

\section{Explorative study}

In this section the behaviour of a single thermo-active pile is further investigated, demonstrating the impact of different aspects of the modelling approach in the simulated response. The same pile and ground conditions, which are typical of 


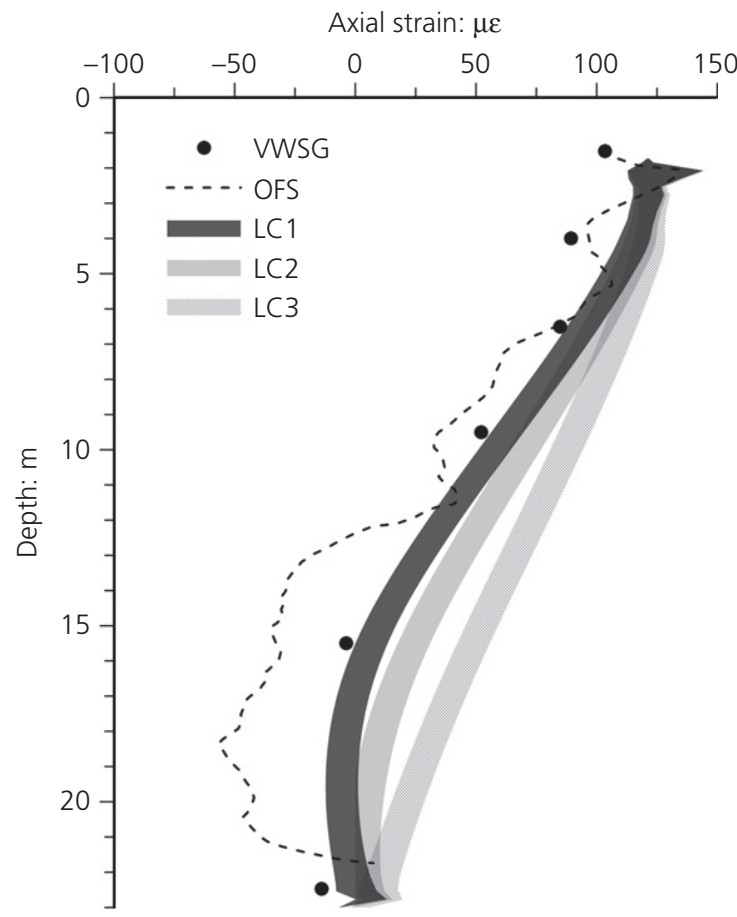

(a)

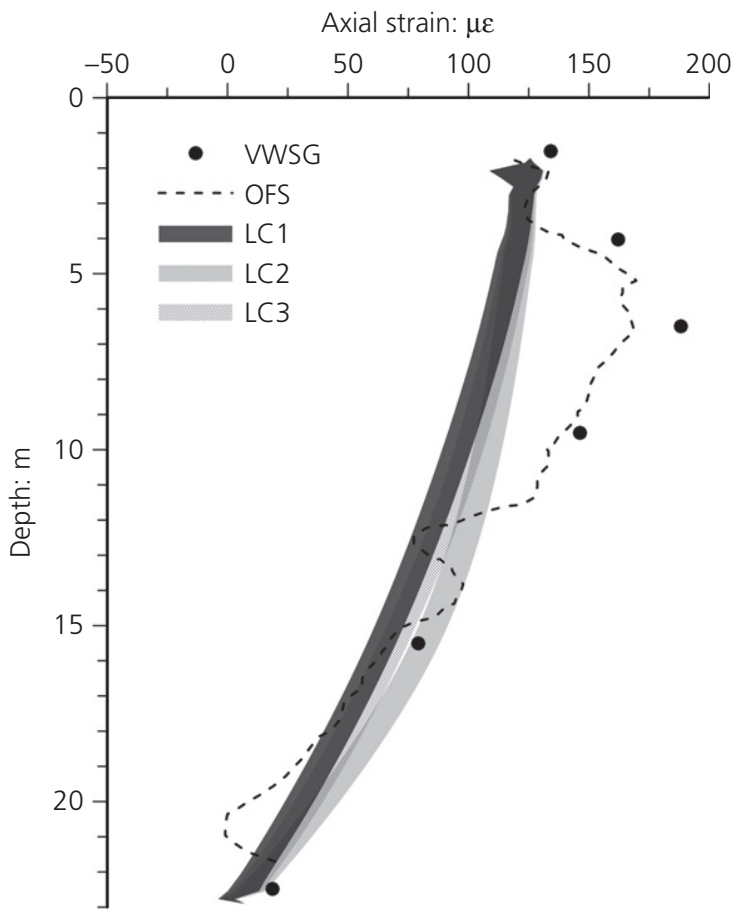

(b)

Figure 9. Axial strain profiles (a) at end of cooling stage and (b) at end of heating stage

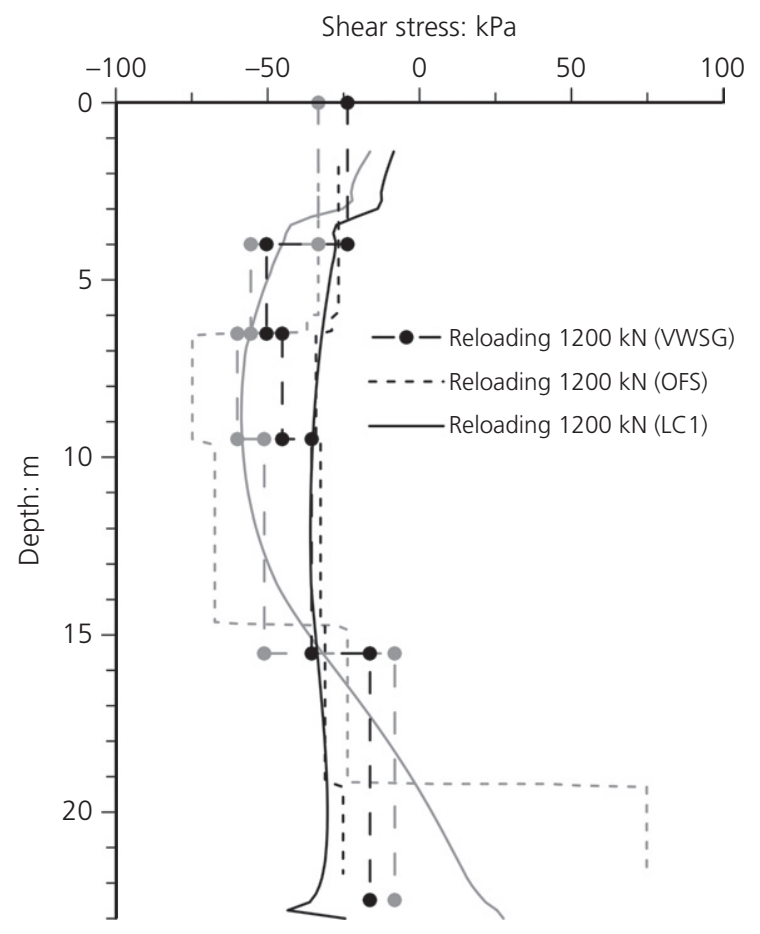

(a)

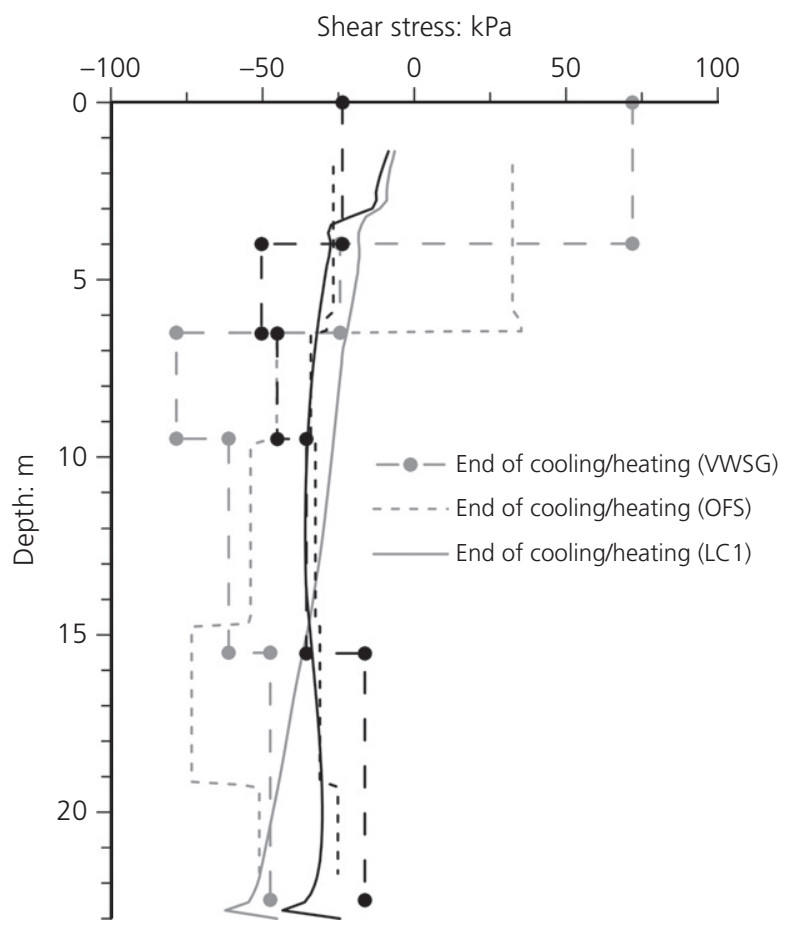

(b)

Figure 10. Shear stress profiles (a) at end of cooling stage and (b) at end of heating stage in analysis LC1 


\begin{tabular}{|c|c|c|c|c|}
\hline Analysis & Analysis type & Thermal load & Soil thermal conductivity & Soil permeability \\
\hline A & Coupled THM & Uniform temperature across pile & $\lambda$ & $k_{0}, B$ \\
\hline B1 & Undrained with heat transfer & Uniform temperature across pile & $\lambda$ & NA \\
\hline B2 & Undrained without heat transfer & Uniform temperature across pile & NA & NA \\
\hline C & Coupled THM & Heat flux across pile & $\lambda$ & $k_{0}, B$ \\
\hline D1 & Coupled THM & Uniform temperature across pile & $2 \lambda$ & $k_{0}, B$ \\
\hline D2 & Coupled THM & Uniform temperature across pile & $0 \cdot 5 \lambda$ & $k_{0}, B$ \\
\hline E1 & Coupled THM & Uniform temperature across pile & $\lambda$ & $10 k_{0}, B$ \\
\hline E2 & Coupled THM & Uniform temperature across pile & $\lambda$ & $0 \cdot 1 k_{0}, B$ \\
\hline
\end{tabular}

Table 5. List of analyses

the London basin, as in the Lambeth College test were considered here.

\subsection{Numerical analysis}

The finite-element mesh, material properties, as well as initial and boundary conditions adopted in this study were, unless otherwise stated, the same as those used in the back-analysis of the Lambeth College test. In this explorative study, the pile was initially loaded to $1200 \mathrm{kN}$, followed by a 1 -year cycle comprising 6 months of energy extraction and 6 months of injection. It should be noted that the excess pore water pressures generated during the mechanical loading were allowed to dissipate before the start of the thermal cycle in order to separate the thermal from the mechanical loading effects.

A series of analyses was performed in order to investigate the effects of the modelling approach, the thermal load application, as well as thermal conductivity and permeability of the soil. All analyses presented in this paper are summarised in Table 5 .

Analysis A, which was used as a baseline for the remaining analyses, is a fully coupled THM analysis where the thermal load was applied as a uniform temperature across the pile. Following the mechanical loading, the pile was cooled by $15^{\circ} \mathrm{C}$ for 5 months (i.e. $T_{\mathrm{p}}=4 \cdot 5^{\circ} \mathrm{C}$ ), heated by $30^{\circ} \mathrm{C}$ for 6 months (i.e. $T_{\mathrm{p}}=34 \cdot 5^{\circ} \mathrm{C}$ ) and finally cooled by $15^{\circ} \mathrm{C}$ for 1 month (i.e. $T_{\mathrm{p}}=19 \cdot 5^{\circ} \mathrm{C}$ ). The temperature change was applied gradually at a rate of $0.05^{\circ} \mathrm{C} / \mathrm{d}$ and, once the total temperature change was achieved, it was kept constant. Following the findings from the back-analysis, the soil stiffness was reset at the end of mechanical loading, at the end of the first cooling and at the end of heating.

In analysis B1, consolidation was not taken into account and the London Clay and Lambeth Group Clay were modelled as undrained materials. However, heat transfer in the soil was still simulated. The modelling approach was simplified further in analysis B2 where the heat transfer through the soil was not taken into account.
Another method of thermal load application was investigated in analysis C. Instead of a uniform temperature change, a heat flux boundary condition was prescribed over the volume of the pile. To simulate heat extraction, a constant heat flux of $-0 \cdot 24 \mathrm{~kW} / \mathrm{m}^{3}$ was applied (this rate corresponds to $-57 \mathrm{~W} / \mathrm{m}$ if the pile is idealised as a linear heat source), whereas heat injection was modelled with a constant heat flux $+0 \cdot 26 \mathrm{~kW} / \mathrm{m}^{3}$ (equivalent to $+62 \mathrm{~W} / \mathrm{m}$ ).

In analyses D1 and D2 the effect of the thermal conductivity of the soil was studied by using values that are larger and smaller, respectively, than the values in analysis A. Similarly, the effect of permeability was investigated in analyses E1 and E2 by varying the magnitude of the parameter $k_{0}$ in Equation 8, which does not affect the initial pore water pressure profile shown in Figure 1.

\subsection{Results}

\subsubsection{Transient thermo-mechanical pile behaviour}

Analysis A was performed in order to provide a baseline for analyses B to E and explain the time-dependent behaviour of a thermo-active pile. Figure 11(a) shows the vertical displacement of the pile along its length, whereas Figure 11(b) presents the shear stress on the pile at different stages of the analysis. The application of the mechanical load causes the pile to move downwards, and therefore, generation of upward (i.e. negative according to the convention adopted in this paper) shear stresses. During the subsequent cooling, the pile contracts, resulting in further downward displacement of the pile head and an upward movement of the pile toe. This process also affects the shear stresses, leading to an additional upward shear stress in the upper part of the pile and a downward shear stress in its lower part. During the next 4 months, while the pile temperature remains constant, the soil continues to cool down and contract. This results in the pile moving further down uniformly along its length, as well as in a decrease in the thermally induced shear stress changes as the restriction imposed by the soil to the pile movement reduces. The inverse of this behaviour can be observed during the subsequent heating 
Pile vertical displacement: $m$

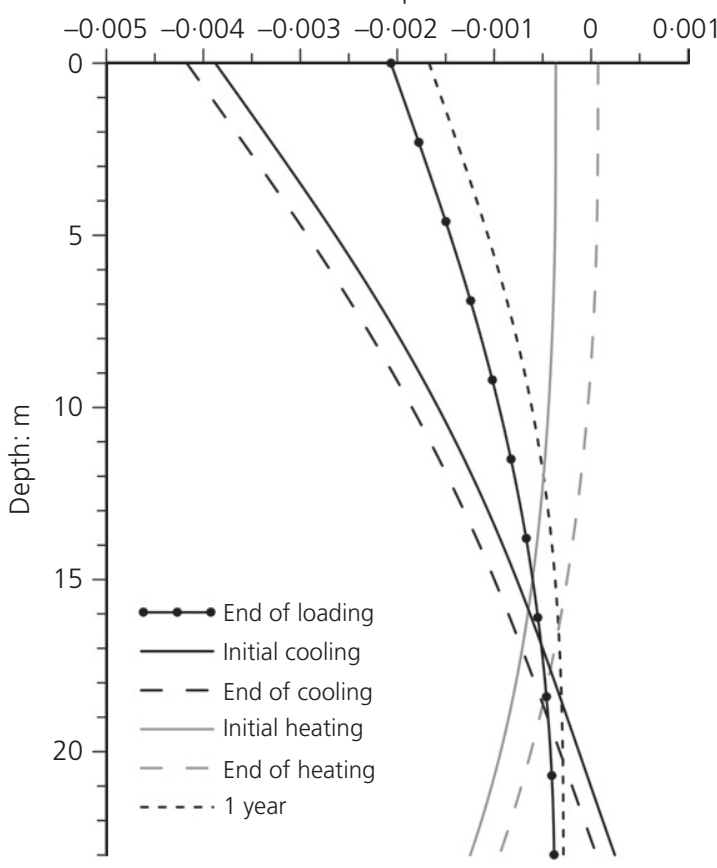

(a)

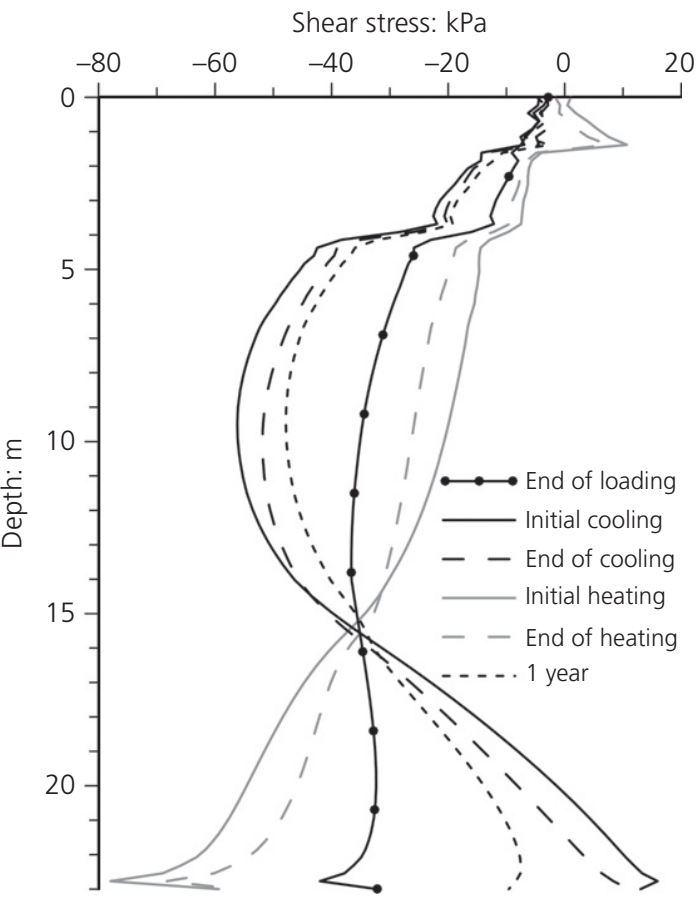

Axial stress: $\mathrm{kPa}$

(b)

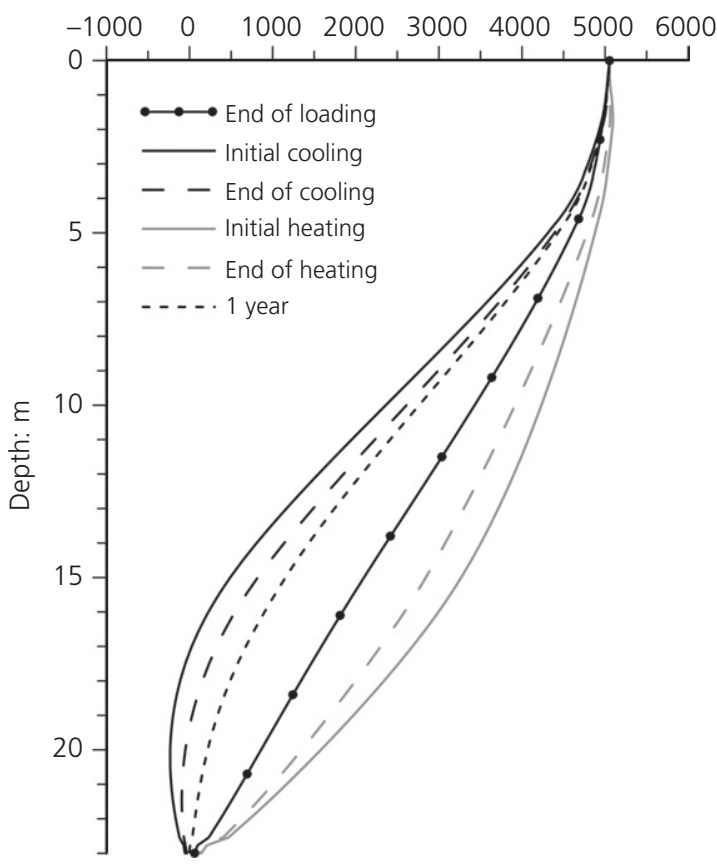

(c)

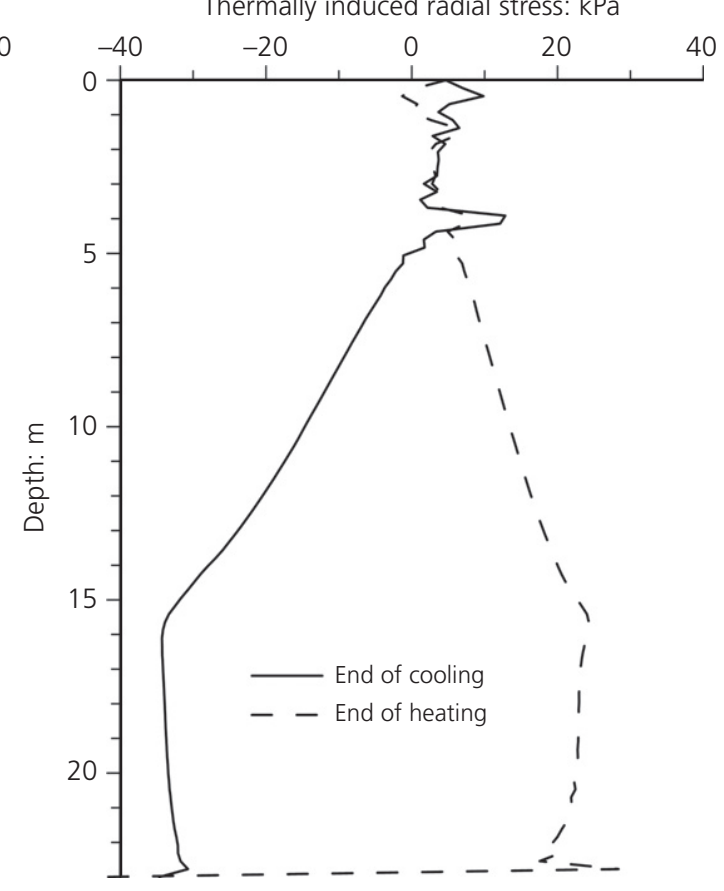

(d)

Figure 11. Results of analysis A: (a) pile vertical displacement along its length, (b) pile shear stress along its length, (c) pile axial stress along its length, (d) pile thermally-induced normal stress changes along its length 
period, where both the pile and the soil expand, reversing the shear stress changes on the pile.

Figure 11(c) shows the total axial stress in the pile at the stages of the analysis mentioned above. Upon cooling, the soil's restriction to the pile movement leads to tensile thermally induced axial stress changes which reduce the total compressive axial stress in the pile. However, as the soil continues to cool down with time, this restriction is alleviated, and hence, the thermally induced axial stresses reduce. Nonetheless, tensile axial stresses may lead to cracking of the concrete, and therefore, the pile must be checked for tensile capacity during the design process. The subsequent heating induces additional compressive stresses in the pile. In this particular case, these stresses do not exceed the maximum axial stress at the top of the pile, however, the magnitude of these additional compressive stresses may increase in other cases (for example if the heating load is increased), and therefore it must be verified during the design procedure.

Contraction and expansion of the pile during cooling and heating also affect the normal stresses from the soil acting on the pile, as shown in Figure 11(d). As expected, cooling induces tensile normal stress changes, whereas heating results in additional compressive normal stresses. However, it should be noted that, while changes in radial stress can have an impact on the pile's ability to mobilise shaft friction, the magnitude of these changes is relatively small compared to the normal effective stresses acting on the pile prior to thermal loading.

Figure 12 shows the changes in pore water pressure during the thermal operation. During the first month of cooling, the deformation of the pile, as well as the difference in the thermal expansion coefficient of soil particles and pore water, cause the generation of tensile pore pressures changes around the pile with a maximum amplitude of approximately $30 \mathrm{kPa}$. Over the following 4 months, these pore pressure changes reduce noticeably, although there is an increase in the volume of soil affected as the cooling front propagates. Conversely, heating induces compressive pore water pressure changes, as shown in Figures 12(c) and 12(d). It should be noted that, in the case considered here, the changes in pore water pressure during cooling and heating are relatively insignificant.

\subsubsection{Effect of modelling approach}

Comparison between analyses $\mathrm{A}, \mathrm{B} 1$ and $\mathrm{B} 2$ demonstrates the effect of including the transient phenomena of consolidation

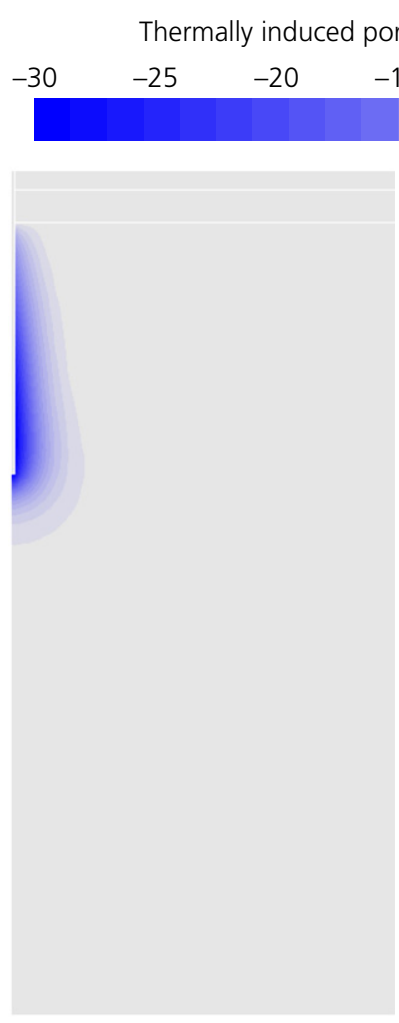

(a) (b)

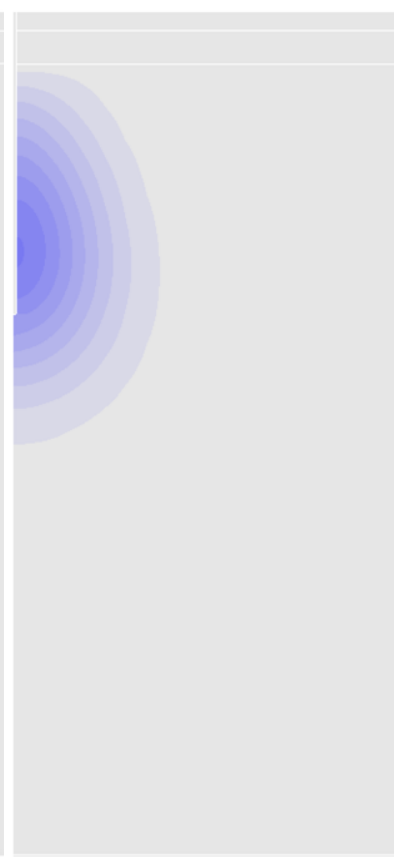

Figure 12. Thermally induced pore water pressure changes (a) after initial cooling, (b) at the end of cooling, (c) after initial heating and (d) at the end of heating in analysis $A$

Thermally induced pore water pressure: $\mathrm{kPa}$

$\begin{array}{lllllllll}-5 & 0 & 5 & 10 & 15 & 20 & 25 & 30 & 35\end{array}$

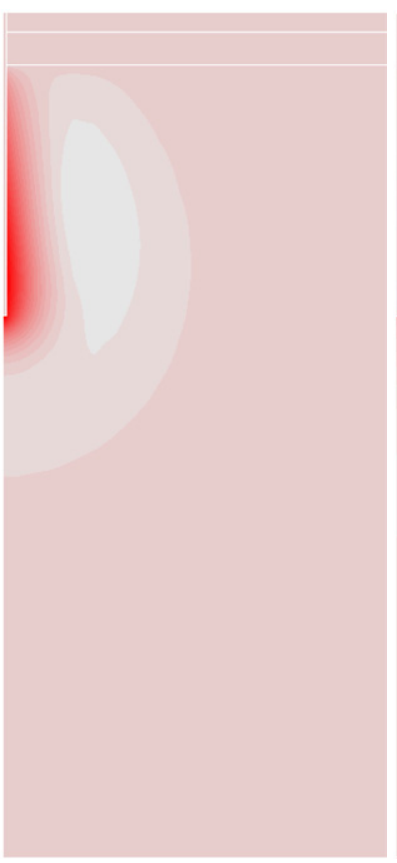

(c)

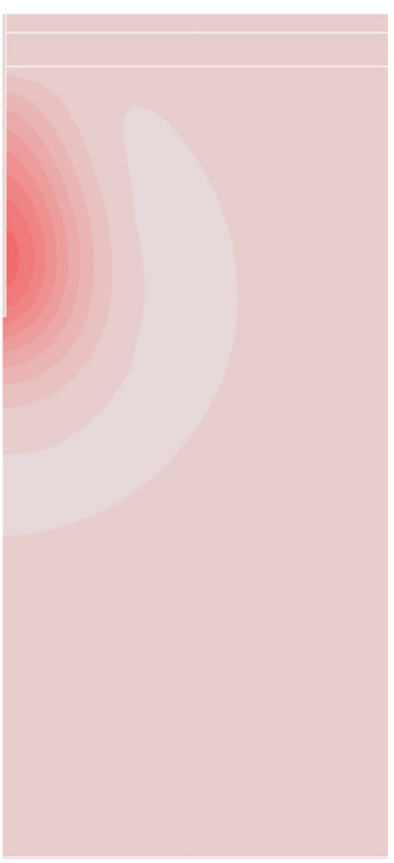

(d) 
and heat transfer in the soil. Figure 13(a) shows that the vertical displacement of the pile head is greatest in analysis B1 and smallest in analysis B2. As neither consolidation, nor heat transfer in the soil are simulated in analysis B2, following the initial contraction of the pile due to cooling, as well as the initial expansion on heating, no further changes take place in the soil and the pile does not move. In analysis B1, the heat transfer through the soil is modelled, and therefore, the pile continues to move downwards as more soil around it cools down and contracts. Similarly, during heating, the pile's upward movement is enhanced by the thermal expansion of the soil. Although the soil contraction/expansion is also simulated in the coupled THM analysis (analysis A), the downward displacement of the pile on cooling is partially compensated by the swelling of soil during dissipation of the generated tensile pore pressures. During heating, the soil consolidates as the excess pore pressures dissipate, which slightly reduces the upward movement of the pile due to thermal expansion.

These differences in the displacement of the pile lead to different shear and axial stresses, as depicted in Figures 13(b) and 13(c). In analysis B2, the soil does not contract or expand, and therefore, it imposes the greatest restriction to the movement of the pile and leads to the largest changes in shear and axial stresses. Conversely, in analyses A and B1, the soil deforms in a similar manner to the pile, which reduces the restriction to the pile and results in smaller changes in shear and axial stresses.

The evolution of the maximum thermally induced axial stress changes, which appear around the null point of the pile, is shown in Figure 13(d). It is clear that performing a simplified undrained analysis without heat transfer in the soil (analysis B2) overestimates changes in axial stress by up to $78 \%$ and leads to a highly conservative design. On the contrary, simulating the heat transfer but neglecting the effects of coupled consolidation underpredicts the changes in axial stresses, albeit by a more limited margin. It is interesting to note that analysis B2 could be seen as the finite-element equivalent to the loadtransfer method, as it does not account for the thermo-hydraulic soil behaviour.

\subsubsection{Effect of thermal load application}

In all numerical analyses presented so far in this paper, the thermal load was applied to the pile as temperature. However, it may sometimes be more appropriate to consider the thermal load as a flux of heat, especially when the pile is required to inject or extract energy at a prescribed rate. In this section, the previously discussed analysis $\mathrm{A}$ is compared to analysis $\mathrm{C}$ where, instead of the temperature boundary condition, a heat flux boundary condition is prescribed over the volume of the pile. In order for the two analyses to be comparable, the magnitude of the heat flux was chosen such that the temperature at the circumference of the pile, at the end of the cooling and the heating periods was the same for both analyses, as illustrated in Figure 14(a). This condition was achieved by applying a constant heat flux of $-0.24 \mathrm{~kW} / \mathrm{m}^{3}$ (which corresponds to $-57 \mathrm{~W} / \mathrm{m}$ ) during the first 5 months of energy extraction, $+0 \cdot 26 \mathrm{~kW} / \mathrm{m}^{3}$ (or $+62 \mathrm{~W} / \mathrm{m}$ ) during the following 6 months of heat injection and $-0 \cdot 26 \mathrm{~kW} / \mathrm{m}^{3}$ over the final month. Figure 14(a) shows that the temperature evolution is different in the two cases, as expected. In analysis $\mathrm{C}$, the initial rate of temperature change is larger than in analysis $\mathrm{A}$, however, it becomes smaller after approximately $10 \mathrm{~d}$.

The vertical displacement of the pile head shown in Figure 14 (b) also reflects this trend. The pile initially contracts and expands more in analysis $\mathrm{C}$, but reaches the same displacement at the end of the cooling and heating periods.

The maximum thermally induced axial stresses in Figure 14(c) show initially a larger change in analysis $\mathrm{C}$ than in analysis $\mathrm{A}$, however, as the rate of temperature change reduces, the axial strains remain approximately constant. Furthermore, it is interesting to note that analyses with constant temperature may lead to unconservative results. Although in this particular case the difference between the two approaches is relatively small and may not affect the pile design, in other cases the difference may be more significant and, therefore, it may need to be accounted for.

\subsubsection{Effect of thermal conductivity}

Laboratory or in situ measurements of soil thermal conductivity are rarely available, hence the design of thermo-active piles, particularly at an early stage, may require assumptions regarding its magnitude. In this section, the effect of this thermal property is investigated by respectively increasing (analysis D1) and reducing (analysis D2) the values used in analysis A by a factor of two.

Thermal conductivity controls the rate at which heat is transferred through conduction, with a larger value of thermal conductivity indicating a quicker cooling and heating of the material. Therefore, for a given time instant, soil in analysis D1 experiences higher changes in temperature than those observed in analysis D2. This can be seen clearly in Figure 15(a), which shows that the pile movement is greatest in analysis D1 resulting from a larger volume of soil experiencing thermal contraction or expansion.

Figure 15(b) shows that the maximum thermally induced axial stress changes are higher in analysis D2 than analysis D1. This can be explained by the fact that, in analysis D1, the soil cools down and heats up quicker, therefore contracting and expanding more than in analysis D2. This results in a smaller mechanical restriction to the movement of the pile, and therefore, smaller changes in axial stresses.

\subsubsection{Effect of permeability}

The last part of the performed study investigates the effect of soil permeability on the behaviour of a thermo-active piles. 


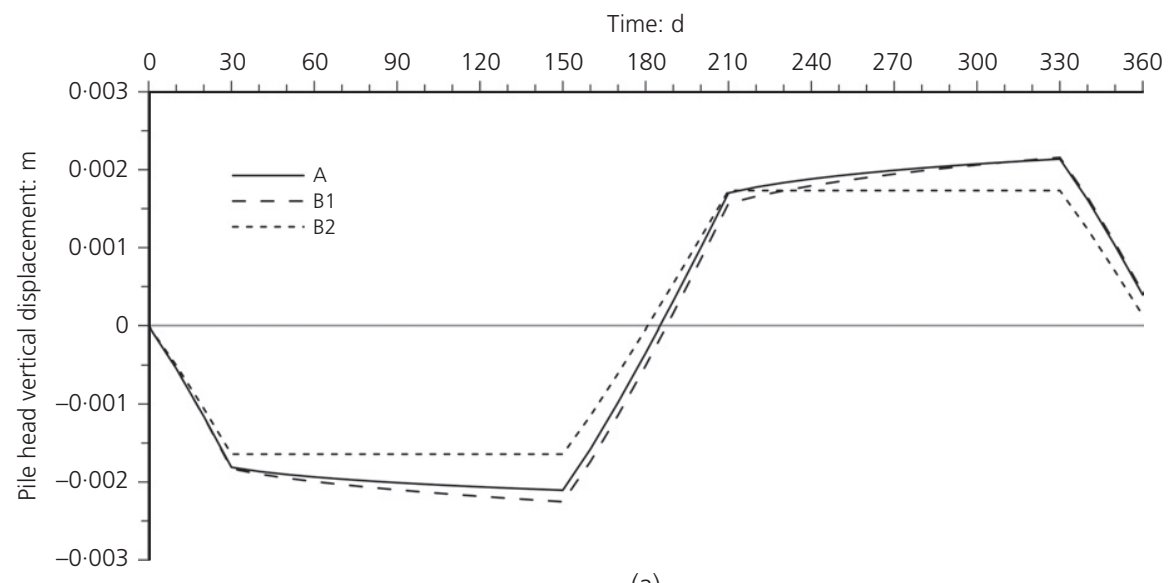

(a)

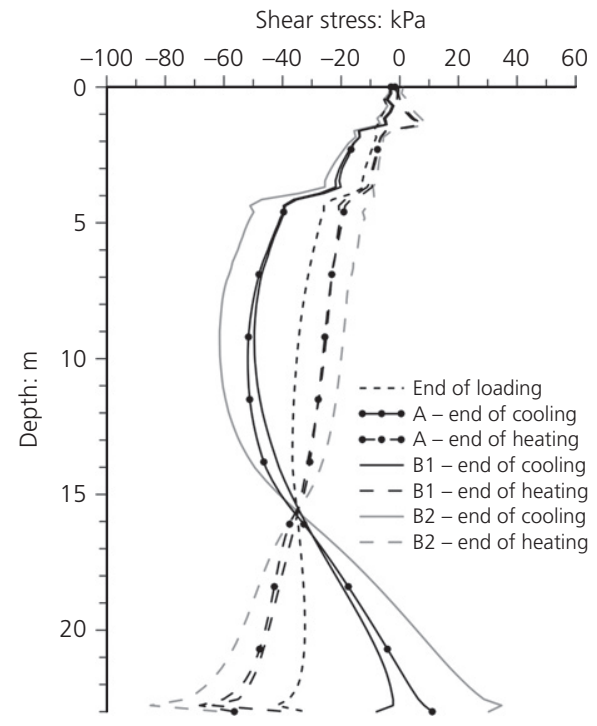

(b)
Axial stress: $\mathrm{kPa}$

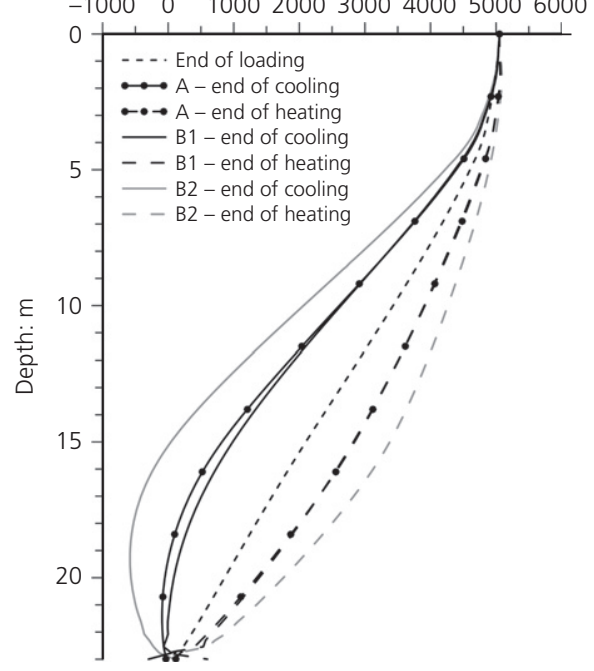

(c)

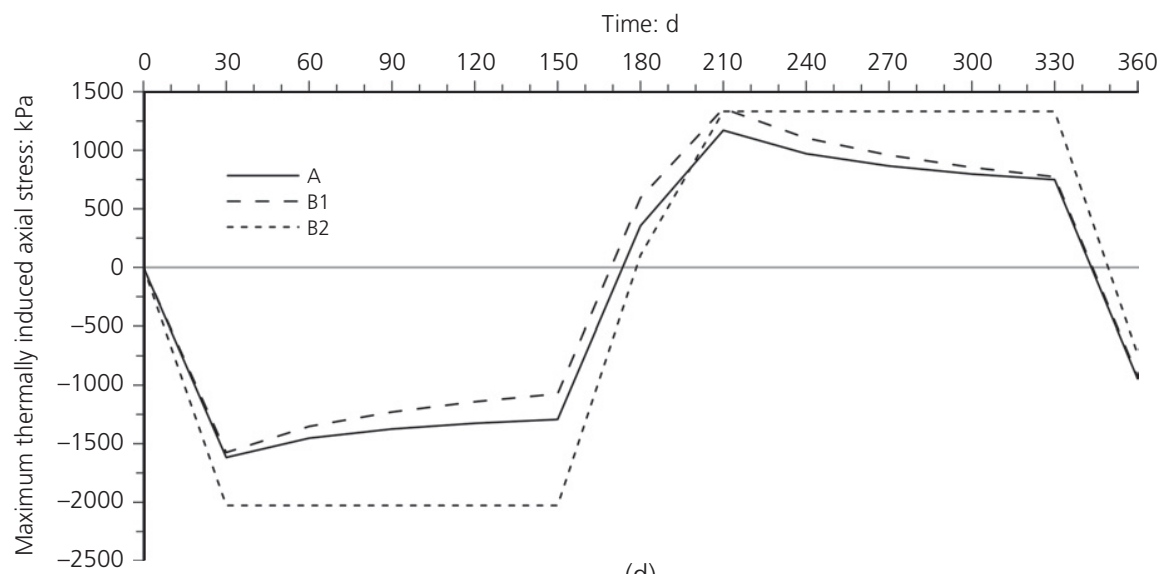

(d)

Figure 13. Results of analyses A, B1 and B2: (a) evolution of pile head vertical displacement with time; (b) pile shear stress along its length; (c) pile axial stress along its length; (d) evolution of maximum thermally induced axial stress with time 


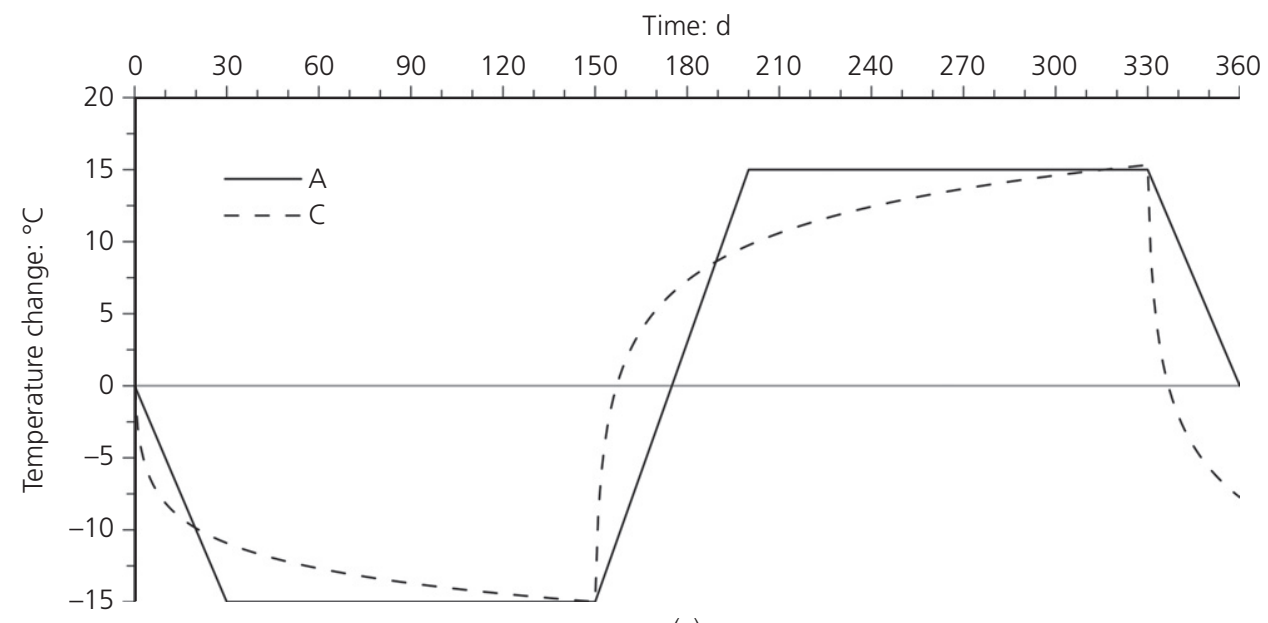

(a)

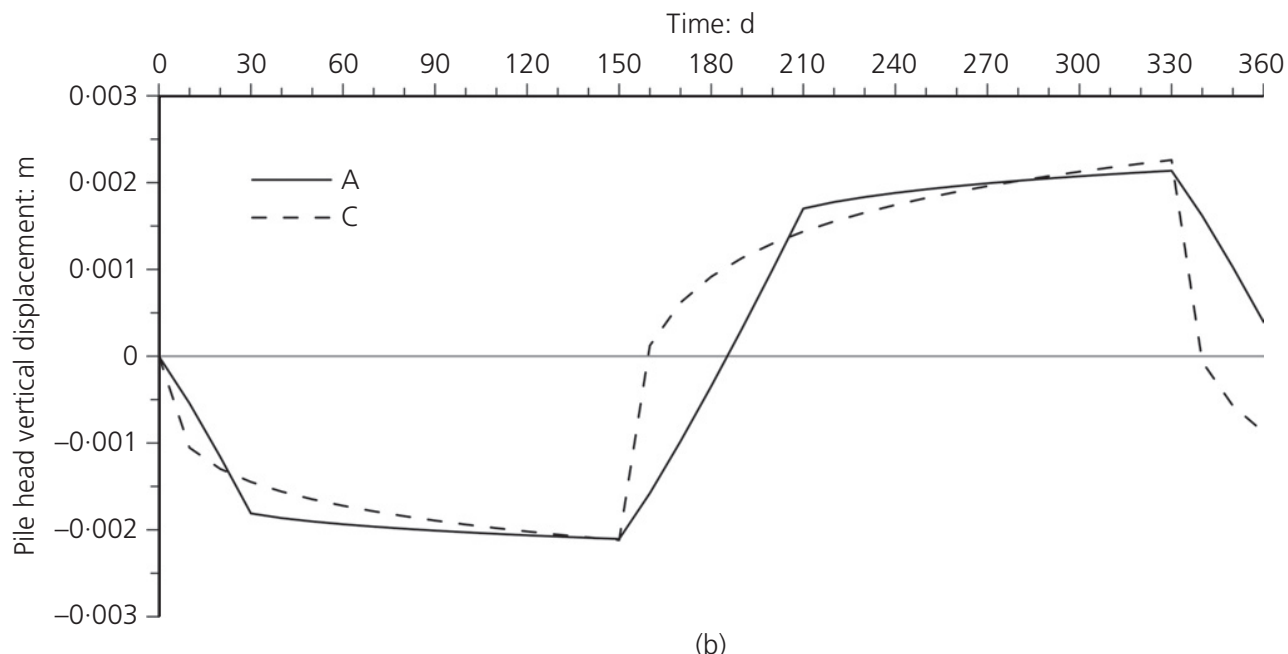

(b)

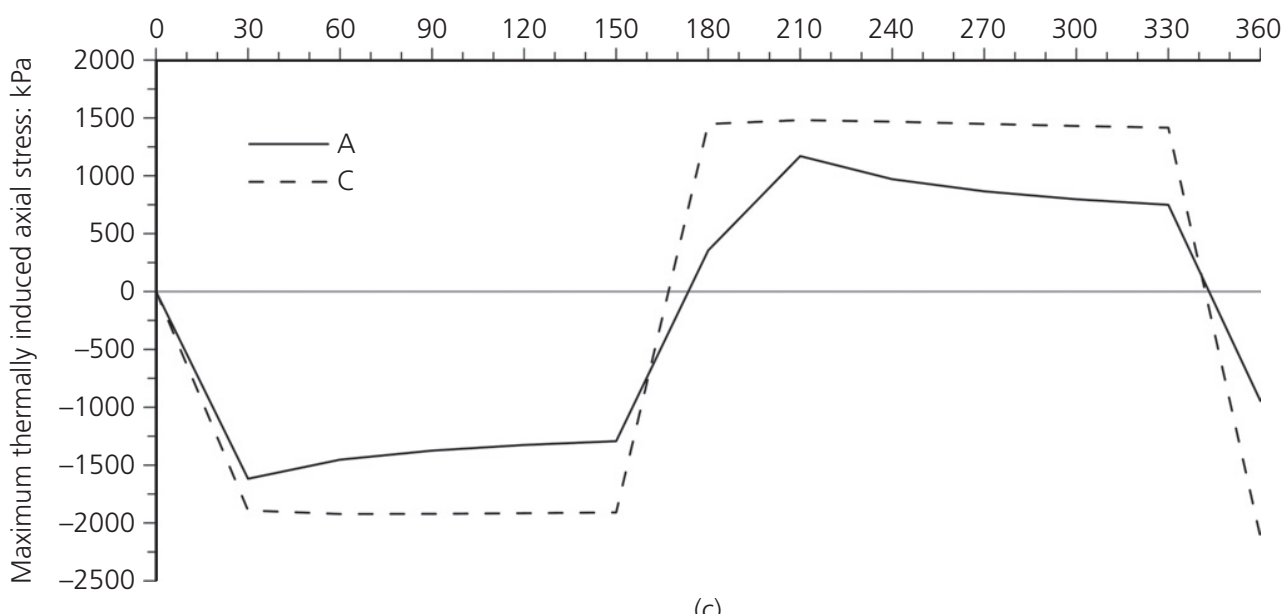

Figure 14. Results of analyses A and C: (a) evolution of temperature at the circumference of the pile; (b) evolution of pile head vertical displacement with time; (c) evolution of maximum thermally induced axial stress with time 


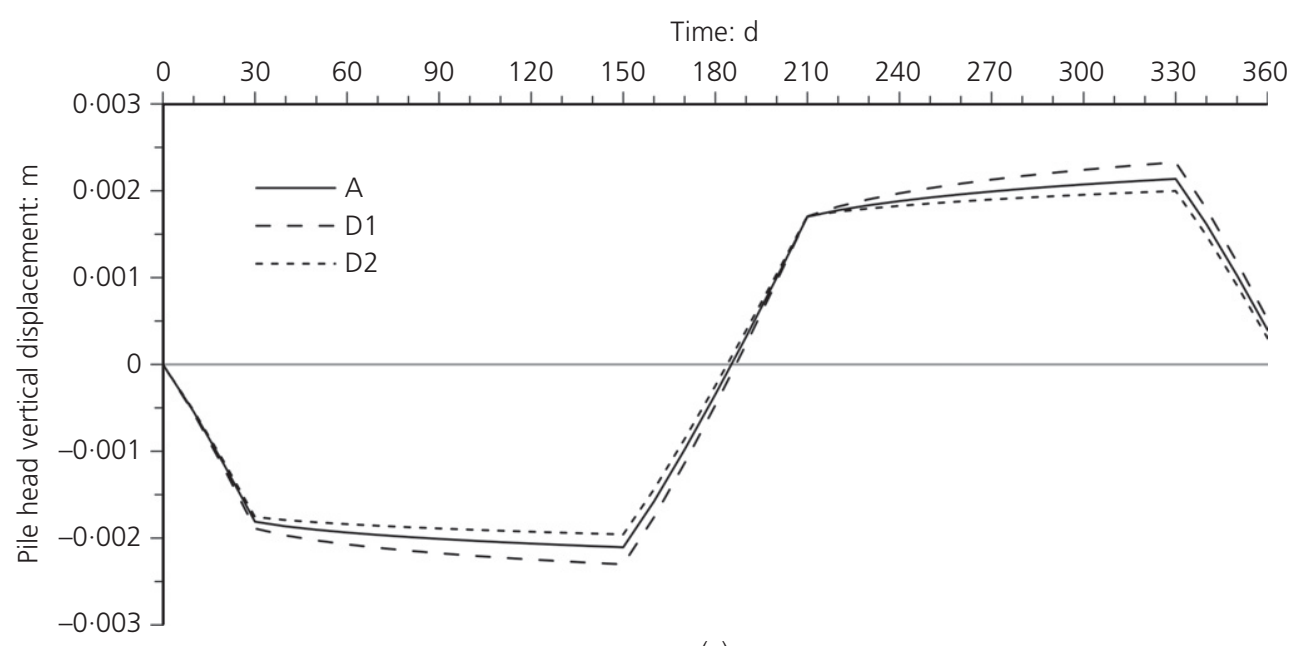

(a)

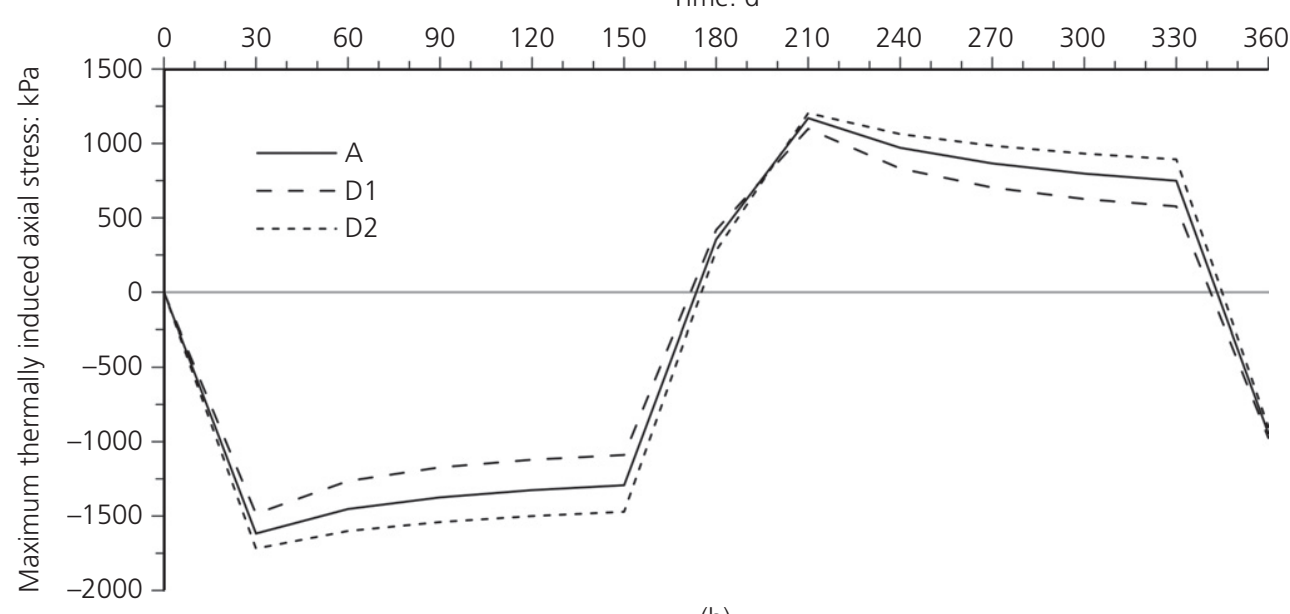

(b)

Figure 15. Results of analyses A, D1 and D2: (a) evolution of pile head vertical displacement with time; (b) evolution of maximum thermally induced axial stress with time

In analysis E1, the permeability was increased by multiplying the $k_{0}$ parameter in Equation 8 by 10 , whereas in analysis E2, $k_{0}$ was divided by 10 . As the value of parameter $B$ remained the same, the initial pore water pressure profile depicted in Figure 1 did not change.

Permeability affects the rate of dissipation of pore water pressures and consolidation. The displacement of the pile head shown in Figure 16 is largest in analysis E2, which simulates a less permeable material, and therefore, slower dissipation of excess pore water pressures. This suggests that the pile movement is mostly controlled by the thermal contraction and expansion of the soil. It should be noted that this response is similar to that in the undrained analysis B1. Conversely, in analysis E1, the pore pressure dissipation is faster, allowing for additional swelling of the soil during cooling and consolidation upon heating, which partially compensate for the thermal contraction and expansion of the soil and result in smaller overall movements of the pile.

Figure 17 shows the changes in pore water pressure in analysis E2 taking place from the start of the thermal cycles. After the first month of cooling, the maximum thermally induced pore pressure is approximately $-110 \mathrm{kPa}$ compared to $-30 \mathrm{kPa}$ in the reference analysis (analysis A). During the subsequent 4 months, these pore pressures increase to a value of approximately $-47 \mathrm{kPa}$, which is still larger than the maximum tensile value in analysis A. It should be noted that the change in pore pressures in analysis E1 were very small from the beginning of the thermal operations due to a quick dissipation of excess pore water pressures. Similar trends can be observed during the heating stage. 


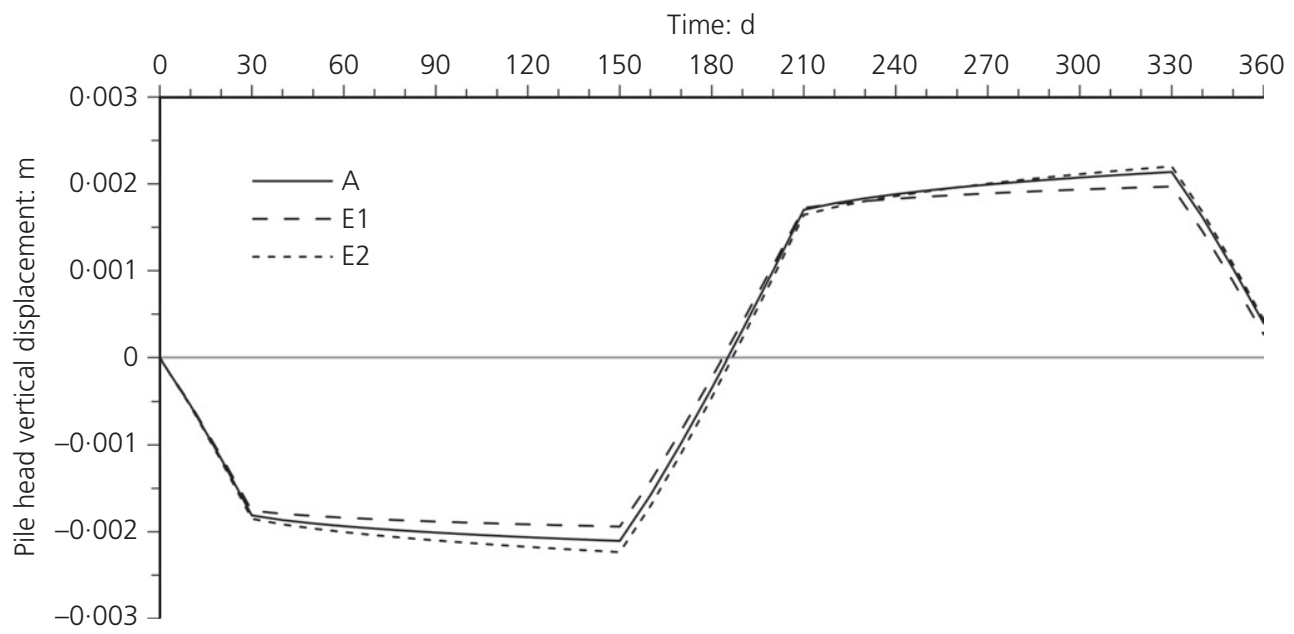

Figure 16. Evolution of pile head vertical displacement with time in analyses A, E1 and E2

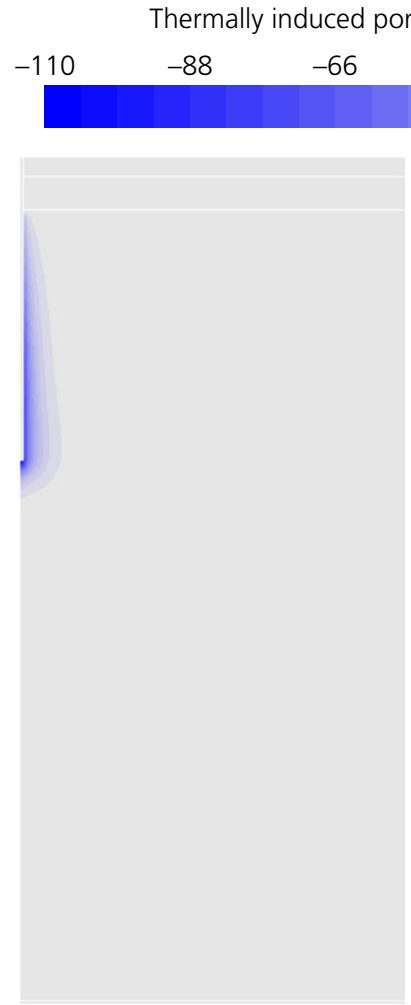

(a) Thermally induced pore water pressure: kPa

$-44$

$0 \quad-10$

10

90

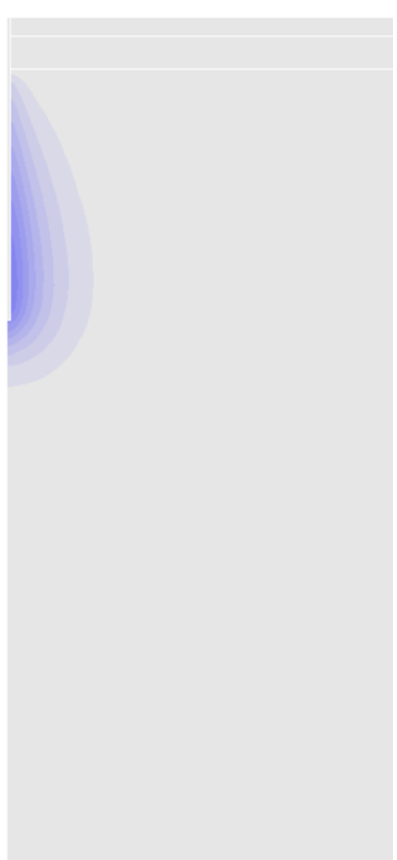

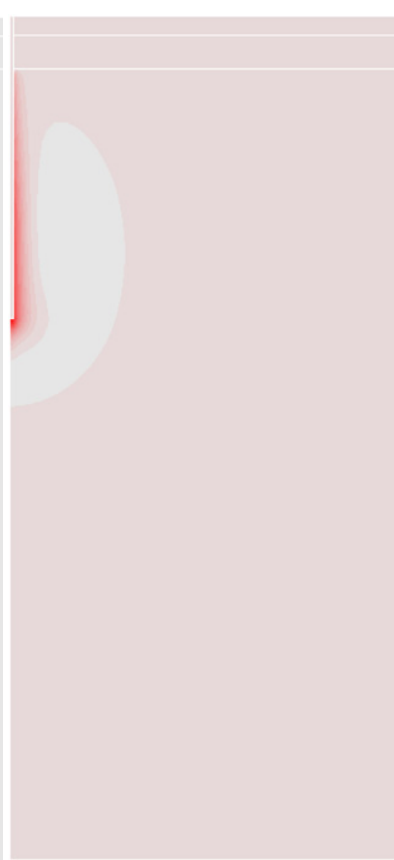

(c)

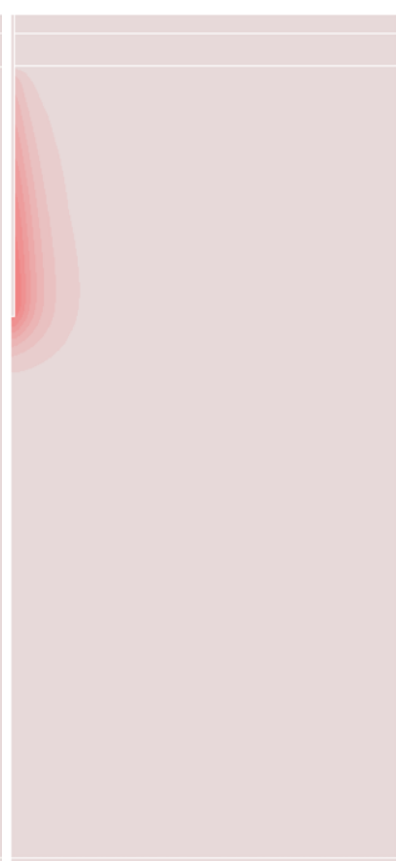

(d)

Figure 17. Thermally induced pore water pressure changes:

(a) after initial cooling; (b) at end of cooling; (c) after initial heating; $(d)$ at end of heating in analysis E2

\section{Conclusions}

In the first part of this paper, the capabilities of the ICFEP to model coupled THM problems was demonstrated by back-analysing the Lambeth College pile test. The close reproduction of the measured temperatures, displacements, strains and stresses was achieved by accounting for the smallstrain stiffness behaviour of the soil, as well as simulation of the transient phenomena of heat transfer and consolidation. 
The thermo-mechanical response of a single pile in ground conditions typical of the London basin was then examined in detail through a series of numerical analyses. The key conclusions can be summarised as follows.

(a) Cooling generates considerable tensile axial stress changes in the pile, and therefore, thermo-active piles must be checked for tensile capacity during the design procedure. Conversely, heating causes compressive axial stress changes whose magnitude may also need to be accounted for during the design procedure.

(b) The thermally induced stress changes tend to reduce with time as the surrounding soil reacts to the changes imposed on the pile.

(c) The modelling approach, in terms of both the analysis type (i.e. coupled as opposed to uncoupled) and the method of thermal load application, can have a large influence on the computed results, and therefore potentially also on the design of such piles. For example, in the case where the transient phenomena in the soil were not taken into account, which is consistent with the load-transfer method, the changes in stresses caused by temperature were significantly higher than those predicted by a fully coupled THM analysis.

(d) For the ground conditions typical of the London basin, varying thermal conductivity and permeability does not affect the behaviour of the pile as significantly as changing the modelling approach.

This study has provided extensive insight into the behaviour of thermo-active piles. It was carried out placing particular emphasis on reproducing ground conditions typical of the London basin, where increasing numbers of thermo-active piles are being installed, and adopting a commonly employed constitutive framework. However, further research, with greater interaction between numerical, field and laboratory investigations, is required to clarify outstanding issues, such as the volumetric changes exhibited by London Clay when subjected to changes in temperature, long-term effects of cycling heating and cooling, and response of pile groups.

\section{Acknowledgements}

The research presented in this paper was funded by the Engineering and Physical Sciences Research Council (EPSRC, grant number: 1386304) and the Geotechnical Consulting Group (GCG).

\section{REFERENCES}

Abdelaziz S and Ozudogru TY (2016) Non-uniform thermal strains and stresses in energy piles. Environmental Geotechnics 3(4): 237-252.

Abuel-Naga HM, Bergado DT, Bouazza A and Ramana GV (2007) Volume change behaviour of saturated clays under drained heating conditions: experimental results and constitutive modeling. Canadian Geotechnical Journal 44(8): 942-956.
Addenbrooke TI, Potts DM and Puzrin AM (1997) The influence of pre-failure soil stiffness on the numerical analysis of tunnel construction. Géotechnique 47(3): 693-712.

Akrouch GA, Sánchez M and Briaud JL (2014) Thermo-mechanical behavior of energy piles in high plasticity clays. Acta Geotechnica 9(3): 399-412.

Amatya BL, Soga K, Bourne-Webb PJ, Amis T and Laloui L (2012) Thermo-mechanical behaviour of energy piles. Géotechnique 62(6): 503-519.

Bailie P (2013) An Investigation into the Cyclic Response of Piles. MSc thesis, Imperial College London, London, UK.

Banks D (2012) An Introduction to Thermogeology: Ground Source Heating and Cooling, 2nd edn. Wiley-Blackwell, Chichester, UK.

Bodas Freitas TM, Cruz Silva F and Bourne-Webb PJ (2013) The response of energy foundations under thermo-mechanical loading. Proceedings of the 18th International Conference on Soil Mechanics and Geotechnical Engineering, Paris, France. ISSMGE, London, UK, pp. 3347-3350.

Bourne-Webb PJ, Amatya B, Soga K et al. (2009) Energy pile test at Lambeth College, London: geotechnical and thermodynamic aspects of pile response to heat cycles. Géotechnique 59(3): 237-248.

Bourne-Webb PJ, Amatya B and Soga K (2013) A framework for understanding energy pile behaviour. Proceedings of the Institution of Civil Engineers - Geotechnical Engineering 166(2): 170-177, http://dx.doi.org/10.1680/geng.10.00098.

Bourne-Webb PJ, Freitas TMB and Assunção RMF (2016) Soil-pile thermal interactions in energy foundations. Géotechnique 66(2): 167-171.

Brandl H (2006) Energy foundations and other thermo-active ground structures. Géotechnique 56(2): 81-122.

Cui W (2015) Development, Implementation and Application of Thermo-Hydro-Mechanical Couplings In Finite Element Analysis. PhD thesis, Imperial College London, London, UK.

Cui W, Gawecka KA, Taborda DMG, Potts DM and Zdravković L (2016) Time-step constraints in transient coupled finite element analysis. International Journal for Numerical Methods in Engineering 106(12): 953-971.

Di Donna A and Laloui L (2015) Numerical analysis of the geotechnical behaviour of energy piles. International Journal for Numerical and Analytical Methods in Geomechanics 39(8): 861-888.

Di Donna A, Rotta Loria AF and Laloui L (2016) Numerical study of the response of a group of energy piles under different combinations of thermo-mechanical loads. Computers and Geotechnics 72: 126-142.

Dupray F, Laloui L and Kazangba A (2014) Numerical analysis of seasonal heat storage in an energy pile foundation. Computers and Geotechnics 55: 67-77.

Headon J, Banks D, Waters A and Robinson VK (2009) Regional distribution of ground temperature in the Chalk aquifer of London, UK. Quarterly Journal of Engineering Geology and Hydrogeology 42(3): 313-323. 
Jardine RJ, Potts DM, Fourie AB and Burland JB (1986) Studies of the influence of non-linear stress-strain characteristics in soil-structure interaction. Géotechnique 36(3): 377-396.

Kalantidou A, Tang AM, Pereira JM and Hassen G (2012) Preliminary study on the mechanical behaviour of heat exchanger pile in physical model. Géotechnique 62(11): 1047-1051.

Knellwolf C, Peron H and Laloui L (2011) Geotechnical analysis of heat exchanger piles. Journal of Geotechnical and Geoenvironmental Engineering 137(10): 890-902.

Laloui L, Nuth M and Vulliet L (2006) Experimental and numerical investigations of the behaviour of a heat exchanger pile. International Journal for Numerical and Analytical Methods in Geomechanics 30(8): 763-781.

Loveridge F and Powrie W (2013) Pile heat exchangers: thermal behaviour and interactions. Proceedings of the Institution of Civil Engineers - Geotechnical Engineering 166(2): 178-196, http://dx.doi.org/10.1680/geng.11.00042.

McCartney JS and Rosenberg JE (2011) Impact of heat exchange on side shear in thermo-active foundations. In Proceedings of Geo-Frontiers 2011, Dallas, USA (Han J and Alzamora DE (eds)). ASCE, Reston, VA, USA, pp. 488-498.

Measham PG, Taborda DMG, Zdravković L and Potts DM (2014) Numerical simulation of a deep excavation in London Clay. In Proceedings of the 8th European Conference on Numerical Methods in Geotechnical Engineering, Delft, The Netherlands (Hicks MA, Brinkgreve RBJ and Rohe A (eds)). Taylor \& Francis, London, UK, pp. 771-776.

Mimouni T and Laloui L (2015) Behaviour of a group of energy piles. Canadian Geotechnical Journal 52(12): 1913-1929.

Murphy KD, McCartney JS and Henry KS (2014) Evaluation of thermo-mechanical and thermal behavior of full-scale energy foundations. Acta Geotechnica 10(2): 179-195.

Ng CWW, Shi C, Gunawan A, Laloui L and Liu HL (2014) Centrifuge modelling of heating effects on energy pile performance in saturated sand. Canadian Geotechnical Journal 52(8): 1045-1057.

Ouyang Y, Soga K and Leung Y (2011) Numerical back-analysis of energy pile test at Lambeth College, London. In Proceedings of Geo-Frontiers 2011, Dallas, USA (Han J and Alzamora DE (eds)). ASCE, Reston, VA, USA, pp. $440-449$.

Ozudogru TY, Olgun CG and Arson CF (2015) Analysis of friction induced thermo-mechanical stresses on a heat exchanger pile in isothermal soil. Geotechnical and Geological Engineering 33(2): 357-371.

Potts DM and Zdravković L (1999) Finite Element Analysis in Geotechnical Engineering: Theory. Thomas Telford, London, UK.

Rotta Loria AF, Gunawan A, Shi C, Laloui L and Ng CWW (2015) Numerical modelling of energy piles in saturated sand subjected to thermo-mechanical loads. Geomechanics for Energy and the Environment 1: 1-15.
Salciarini D, Ronchi F, Cattoni E and Tamagnini C (2015) Thermomechanical effects induced by energy piles operation in a small piled raft. International Journal of Geomechanics 15(2): 1-14.

Schroeder FC, Potts DM and Addenbrooke TI (2004) The influence of pile group loading on existing tunnels. Géotechnique 54(6): 351-362.

Stewart MA and McCartney JS (2013) Centrifuge modeling of soil-structure interaction in energy foundations. Journal of Geotechnical and Geoenvironmental Engineering 140(4): 1-11.

Sultan N, Delage P and Cui YJ (2002) Temperature effects on the volume change behaviour of Boom clay. Engineering Geology 64(2-3): 135-145.

Suryatriyastuti ME, Mroueh $\mathrm{H}$ and Burlon S (2012) Understanding the temperature-induced mechanical behaviour of energy pile foundations. Renewable and Sustainable Energy Reviews 16(5): 3344-3354.

Suryatriyastuti ME, Mroueh H and Burlon S (2014) A load transfer approach for studying the cyclic behavior of thermoactive piles. Computers and Geotechnics 55: 378-391.

Taborda DMG, Potts DM and Zdravković L (2016) On the assessment of energy dissipated through hysteresis in finite element analysis. Computers and Geotechnics 71: 180-194.

Wang B, Bouazza A, Singh RM et al. (2015) Posttemperature effects on shaft capacity of a full-scale geothermal energy pile. Journal of Geotechnical and Geoenvironmental Engineering 141(4): 1-12.

Yavari N, Tang AM, Pereira JM and Hassen G (2014a) Experimental study on the mechanical behaviour of a heat exchanger pile using physical modelling. Acta Geotechnica 9(3): 385-398.

Yavari N, Tang AM, Pereira JM and Hassen G (2014b) A simple method for numerical modelling of mechanical behaviour of an energy pile. Géotechnique Letters 4(2): 119-124.

Yavari NY, Tang AM, Pereira JM and Hassen G (2015) Modelling the mechanical behaviour of an energy pile. In Proceedings of XVI European Conference on Soil Mechanics and Geotechnical Engineering, ECSMGE, Edinburgh, UK (Winter MG, Smith DM, Eldred PJL and Toll DG (eds)). ICE Publishing, London, UK, pp. 2653-2658.

\section{HOW CAN YOU CONTRIBUTE?}

To discuss this paper, please email up to 500 words to the editor at journals@ice.org.uk. Your contribution will be forwarded to the author(s) for a reply and, if considered appropriate by the editorial board, it will be published as discussion in a future issue of the journal.

Proceedings journals rely entirely on contributions from the civil engineering profession (and allied disciplines). Information about how to submit your paper online is available at www.icevirtuallibrary.com/page/authors, where you will also find detailed author guidelines. 